\title{
Article \\ Reduced Granule Cell Proliferation and Molecular Dysregulation in the Cerebellum of Lysosomal Acid Phosphatase 2 (ACP2) Mutant Mice
}

\author{
Xiaodan Jiao ${ }^{1}$, Maryam Rahimi Balaei ${ }^{1}$, Ejlal Abu-El-Rub ${ }^{2,3}$, Filippo Casoni ${ }^{4} \mathbb{D}_{\text {, Hassan Pezeshgi Modarres }}{ }^{\text {, }}$ \\ Sanjiv Dhingra ${ }^{2}$, Jiming Kong ${ }^{1}$ D , Giacomo G. Consalez ${ }^{4}$ and Hassan Marzban ${ }^{1, *}$
}

1 Department of Human Anatomy and Cell Science, The Children's Hospital Research Institute of Manitoba (CHRIM), Rady Faculty of Health Sciences, Max Rady College of Medicine, University of Manitoba, Winnipeg, MB R3E 0W2, Canada; JIAO.XIAODAN@umanitoba.ca (X.J.); rahimibm@myumanitoba.ca (M.R.B.); Jiming.Kong@umanitoba.ca (J.K.)

2 Department of Physiology and Pathophysiology, Institute of Cardiovascular Sciences, St. Boniface Hospital Research Centre, Rady Faculty of Health Sciences, Max Rady College of Medicine, University of Manitoba, Winnipeg, MB R3E 0W2, Canada; eabuelrub@sbrc.ca (E.A.-E.-R.); Sanjiv.Dhingra@umanitoba.ca (S.D.)

3 Physiology and Pathophysiology, Department of Basic Medical Sciences, Faculty of Medicine, Yarmouk University, Irbid 21163, Jordan

4 Division of Neuroscience, San Raffaele Scientific Institute, San Raffaele University, 20132 Milan, Italy; casoni.filippo@hsr.it (F.C.); g.consalez@hsr.it (G.G.C.)

Citation: Jiao, X.; Rahimi Balaei, M.; Abu-El-Rub, E.; Casoni, F.; Pezeshgi Modarres, H.; Dhingra, S.; Kong, J.; Consalez, G.G.; Marzban, H. Reduced Granule Cell Proliferation and Molecular Dysregulation in the Cerebellum of Lysosomal Acid Phosphatase 2 (ACP2) Mutant Mice. Int. J. Mol. Sci. 2021, 22, 2994. https://doi.org/10.3390/ijms2206 2994

Academic Editor: Manoj K. Pandey

Received: 27 January 2021

Accepted: 12 March 2021

Published: 15 March 2021

Publisher's Note: MDPI stays neutral with regard to jurisdictional claims in published maps and institutional affiliations.

Copyright: (C) 2021 by the authors. Licensee MDPI, Basel, Switzerland. This article is an open access article distributed under the terms and conditions of the Creative Commons Attribution (CC BY) license (https:// creativecommons.org/licenses/by/ $4.0 /)$
5 BioMEMS and Bioinspired Microfluidic Laboratory, Department of Mechanical and Manufacturing Engineering, University of Calgary, Calgary, AB T2N 1N4, Canada; hassan.pezeshki@gmail.com

* Correspondence: Hassan.Marzban@umanitoba.ca; Tel.: +1-204-789-3467; Fax: +1-204-789-3920

\begin{abstract}
Lysosomal acid phosphatase 2 (Acp2) mutant mice (naked-ataxia, nax) have a severe cerebellar cortex defect with a striking reduction in the number of granule cells. Using a combination of in vivo and in vitro immunohistochemistry, Western blotting, BrdU assays, and RT-qPCR, we show downregulation of MYCN and dysregulation of the SHH signaling pathway in the nax cerebellum. MYCN protein expression is significantly reduced at P10, but not at the peak of proliferation at around P6 when the number of granule cells is strikingly reduced in the nax cerebellum. Despite the significant role of the $\mathrm{SHH}-\mathrm{MycN}$ pathway in granule cell proliferation, our study suggests that a broader molecular pathway and additional mechanisms regulating granule cell development during the clonal expansion period are impaired in the nax cerebellum. In particular, our results indicate that downregulation of the protein synthesis machinery may contribute to the reduced number of granule cells in the nax cerebellum.
\end{abstract}

Keywords: granule cells; SHH; MYCN; cerebellum; mice; nax

\section{Introduction}

The cerebellum fulfills important roles in motor control, language, attention, and mental imagery [1-3]. This brain region has a three-layered cortex that consists of the molecular layer (ML), Purkinje cell (PC) layer, and granule cell (GC) layer [4,5]. Out of the several types of neurons found in these layers, GCs are the most prominent, comprising approximately $80 \%$ of neurons in the central nervous system (CNS) [6,7].

During cerebellar development, GC precursors arise from the cerebellar rhombic lip and migrate rostrolaterally in a subpial stream to form the external germinal zone (EGZ) from embryonic day (E) 12.5 to 17 [4,8-10]. GC precursors rapidly proliferate in the EGZ and, after 7-8 divisions ( 128-144 h), move radially to their final destination and differentiate into mature GCs [11-14]. During this process, sonic hedgehog (SHH), secreted by PCs, promotes proliferation of GC precursors [15-18]. It has been suggested that SHH signaling pathway effectors may be involved in GC differentiation as well $[19,20]$. The $\mathrm{SHH}$ receptor Patched 1 (PTCH1), together with the co-receptors CDON (Codon), BOC 
(Brother of Codon), and GAS1, functions as a control switch that turns on SHH signal transduction [20-22]. Upon SHH binding to its receptors, PTCH1-mediated inhibition of SMO (Smoothened; a G-coupled transmembrane receptor) is lifted, allowing constitutive SMO activity and associated downstream signaling [23].

The Gli (glioma-associated oncogene homolog) family of proteins plays an important role in downstream SHH signaling [24,25]. The Gli transcription factors include three proteins encoded by the genes Gli1, -2 , and -3 [26]. The zinc finger domains in GLI proteins bind to DNA to initiate or inhibit transcription. Activation of the SHH pathway facilitates the accumulation of GLI1 in the nucleus, leading to the activation of target genes [27]. GLI2 and -3 have been shown to act as activators or inhibitors of transcription, depending on whether or not they have been converted into their repressor (Gli2-R, Gli3-R) forms [28].

Among other GLI target genes, Mycn, located on chromosome 12 in the mouse and encoding the MYCN protein, promotes proliferation of cerebellar GC precursors $[5,29,30]$. In addition to regulating the proliferative cycle of GC precursors, a decrease in MYCN has been reported to act as a switch from proliferation to differentiation [5,30]. Furthermore, GLI factors target cyclins D and $\mathrm{E}$, which together are thought to promote the proliferation of GC precursors in the EGZ [31-34].

Lysosomal acid phosphatase (Acp2), one of many soluble luminal hydrolases, hydrolyzes orthophosphoric monoesters into alcohol and phosphate and removes the mannose6-phosphate recognition marker from lysosomal proteins [35,36]. An Acp2 mutant mouse called nax (naked and ataxia), resulting from a spontaneous point mutation in the Acp2 gene, exhibits an overall impairment of cerebellar cortex development and severe defects in cerebellar function [37]. We have shown that $\mathrm{ACP} 2$ expression marks the caudal midbrain and cerebellum [38], and the anterior cerebellum is the most severely affected in the nax mice [39], which indicate critical and specific roles in cerebellar development. In this mutant, the highly organized three-layered cerebellar cortex is disrupted and the number of cerebellar GCs is significantly reduced [37,39]. In addition, it has recently been shown that dysregulation of the SHH signaling pathway in animal models with lysosomal disorders are implicated in the proliferation of cerebellar GC precursors [40,41].

Based on our current study, we report that the SHH-MycN pathway is impaired in the nax cerebellum, but only after the peak of GC proliferation, between postnatal days $\mathrm{P} 4$ and P8 [42,43]. In the nax cerebellum, defective GC proliferation may be associated with downregulation of the protein synthesis machinery.

\section{Results}

\subsection{The Number of Cerebellar GCs Is Significantly Decreased in the nax Cerebellum}

Previously, we reported that the nax mouse is smaller in size than the wt and shows an overall impairment of the cerebellar cortex and nuclei. The orderly arrangement of the three-layered cerebellar cortex is disrupted in the nax cerebellum with a significant decrease in GCs and excessive migration of PCs [38,39].

In order to assess the differences in the number of cerebellar GCs between the wt and nax cerebella, the neural nuclei (NeuN) antibody was used to label mature GCs. At P13, NeuN immunostaining shows a large number of GCs densely packed in the GC layer of the wt cerebellum (Figure 1A-C), which could not be observed in the nax cerebellum (Figure 1D-F). Further analysis revealed that the number of cerebellar GCs in nax mice is significantly reduced to roughly $20 \%$ of that scored in wt littermates (Figure $1 \mathrm{G}$ ).

This dramatic drop in GCs could be due to a defect in proliferation and/or defective migration from the EGZ (aka external GC layer (EGL)) to the definitive GC layer [44]. To explore whether the proliferative activity of GC precursors is impaired in the EGZ, immunostaining for paired box protein 6 (PAX6) was used to label GC precursors in wt and nax cerebella at $\mathrm{P} 6$, corresponding to the peak of GC precursor clonal expansion. Our results revealed that the number of GC precursors is dramatically decreased in the nax EGZ (Figure 2A,B) and is only about $20 \%$ of that in wt littermates (Figure $2 \mathrm{C}$ ). In order to further confirm this observation and identify GC precursors in the EGZ in relation to 
PC development, we applied double staining for PAX6 and the calcium-binding protein calbindin (CALB), a marker for PCs, in cerebellar sections. At P8, the wt cerebellum shows a thick EGZ containing GC precursors in the medial and lateral cerebellum (Figure 2D,F,G; $\sim 10-12$ layers of the PAX6 $6^{+}$cells). In contrast, the nax mutant cerebellum displays a reduced number of GC precursors in the EGZ, which is hardly detectable near the midline (putative vermis) and very thin in the lateral cerebellum (Figure 2E,H,I; 1-4 layers of the $\mathrm{PAX6}^{+}$cells).

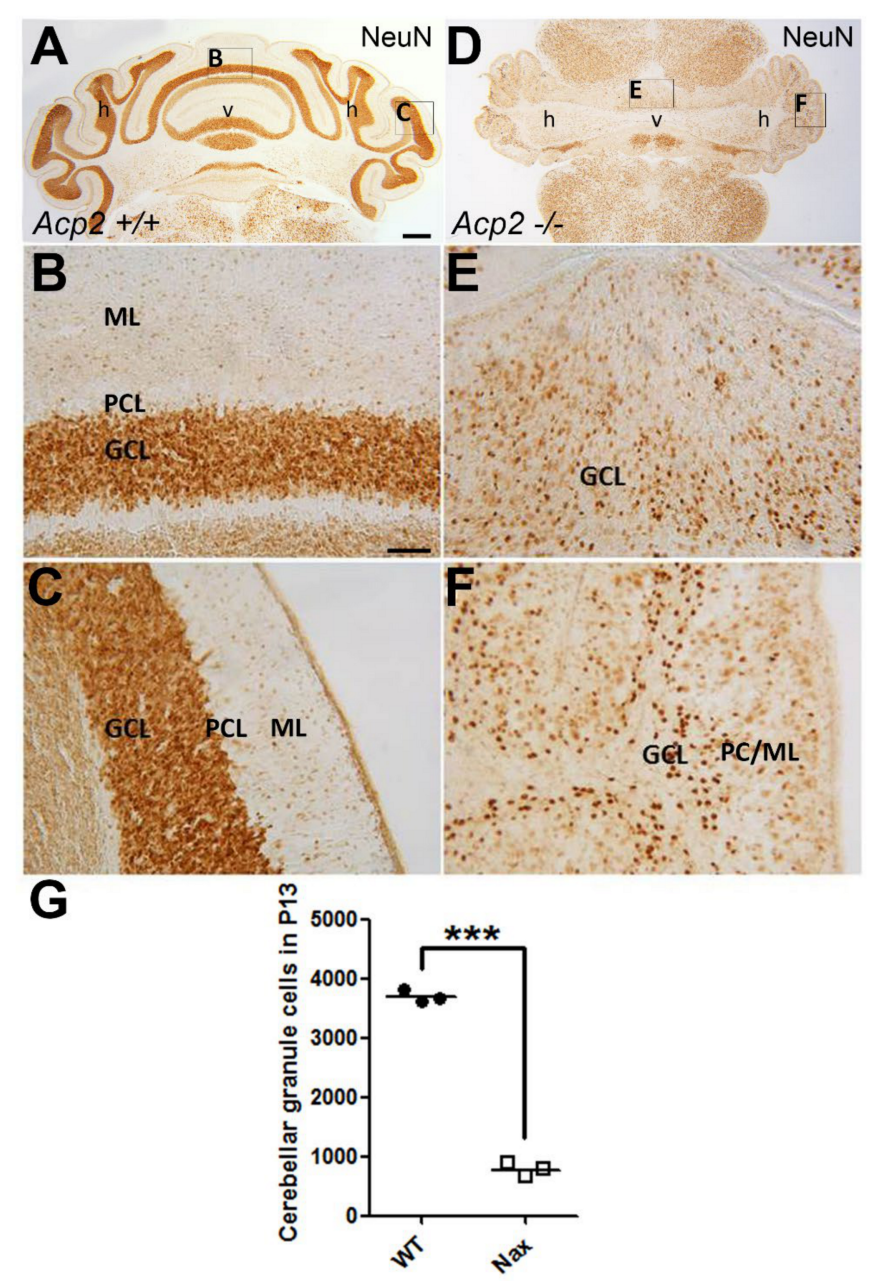

Figure 1. The number of cerebellar granule cells (GCs) is significantly decreased in nax compared to wt littermate mice. (A-C) Frontal section of P13 wt mouse cerebellum immunostained with neuro nuclei (NeuN) reveals a large number of mature GCs in the GC layer (GCL). The higher magnification shows medial (B) and lateral (C) views of the wt cerebellum (A). (D-F) Frontal section of P13 nax mouse cerebellum immunostained with NeuN shows that the cerebellum size is smaller and the lobules are underdeveloped. Evidently, the number of cerebellar GCs is much lower (E,F) than in the wt cerebellum $((\mathbf{B}, \mathbf{C})$ for direct comparison). The higher magnification shows medial (E) and lateral (F) views of nax cerebellum (D). (G) Cell counting of the frontal sections of P13 samples shows a significant difference in the number of GCs between wt and nax cerebella (G). The graph represents the average cell counts at P13 in sections from wt and nax littermates (wt; $n=3$ and nax; $n=3$ ) and shows that the number of GCs amounts to only $\sim 20 \%$ of that scored in wt cerebella. The data in the graph are presented as the mean \pm SEM. Statistical analysis was performed using unpaired $t$-test (*** $p$ <.001). Abbreviations: GCL, GC layer; PCL, PC layer; ML, Molecular layer; $h$, hemisphere; $v$, vermis. Scale bars: $500 \mu \mathrm{m}$ in $(\mathbf{A})$ applies to $(\mathbf{A}, \mathbf{D})$, and $100 \mu \mathrm{m}$ in $(\mathbf{B})$ applies to $(\mathbf{B}, \mathbf{C}, \mathbf{E}, \mathbf{F})$. 

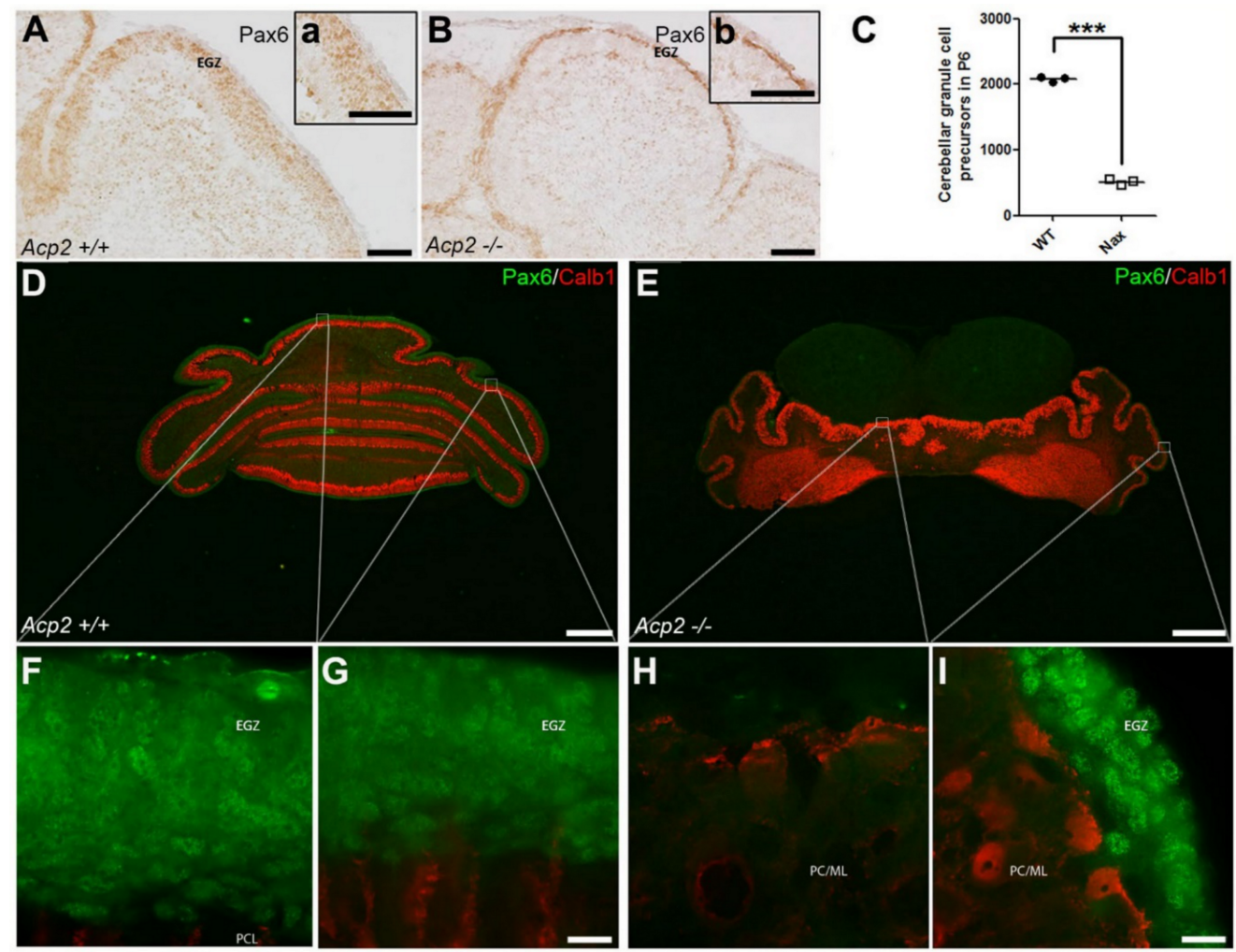

Figure 2. The number of cerebellar GC precursors is decreased in the nax mouse. (A) Sagittal section of P6 wt mouse cerebellum immunostained with PAX6 shows GC precursors in the external germinal zone (EGZ); higher magnification provided in (a). (B) Sagittal section of P6 nax mouse cerebellum immunostained with PAX6 reveals that the number of GC precursors is markedly lower than in the wt cerebellum; higher magnification provided in (b). (C) Cell counting of sagittal sections of P6 cerebellum shows a significant difference in the number of GC precursors during early postnatal age between wt and nax. The bars represent the average cell counts of cerebellar sections obtained at P6 from wt and nax littermates (wt; $n=3$ and nax; $n=3$ ) and show that the number of GC precursors in nax is only about $20 \%$ of that scored in wt. The data in the graph are presented as the mean \pm SEM, and statistical analysis was performed using unpaired $t$-test ${ }^{* * *} p<0.001$. (D-I) Frontal sections of wt (D) and nax (E) cerebellum at P8 immunostained with PAX6 (green) and CALB (red). (D) In the wt cerebellum, a thick external germinal zone (EGZ) could clearly be observed medially (F) and laterally (G). (E) In the nax mutant, the number of proliferating GCs was strongly reduced in the EGZ as compared to the wt; GCs appeared completely absent medially $(\mathbf{H})$, and only a thin EGZ could be identified laterally (I). Abbreviations: EGZ, external germinal zone; ML, molecular layer; PCL, Purkinje cell layer. Scale bars: $500 \mu \mathrm{m}$ in (A,B), $100 \mu \mathrm{m}$ in (a,b), $1000 \mu \mathrm{m}$ in (D,E), $20 \mu \mathrm{m}$ in (G) applies to (F-G), and $20 \mu \mathrm{m}$ in (I) applies to $(\mathbf{H}, \mathbf{I})$.

Bergmann glial cells are involved in GC migration, the original concept of glialguided neuronal migration [45]. Glial fibrillary acidic protein (GFAP) immunostaining in wt (Supplementary Figure S1A-C) and nax (Supplementary Figure S1D-F) cerebella showed that Bergmann glial cell bodies are present in both groups but are scattered in the PC/molecular layer in the nax cerebellum. This can likely be explained by the observation that the multilayer PCs stomata in the molecular layer and Bergmann glial fibers at different lengths are still extending toward the pia mater. To examine whether the proliferating GC precursors migrate to the GC layer, BrdU incorporation was studied. BrdU administration at E18 and subsequent immunostaining at P5 revealed that GCs migrated from the EGZ to the granular layer in the nax cerebellum (Figure 3B; arrows in inset), comparable to wt littermates (Figure $3 \mathrm{~A}$; arrows in inset). NeuN immunostaining of serial sections confirmed the presence of mature GCs in the granular layer of the wt (Figure 3C) and nax cerebellum (Figure 3D). To determine whether GC precursor proliferation is 
decreased in the nax cerebellum, the mice were injected with BrdU at P6 and studied $45 \mathrm{~min}$ after injection (Figure 4). BrdU immunostaining revealed that GC proliferation is dramatically decreased in the cerebella of nax mice to roughly $30 \%$ (Figure $4 B, D, G$ ) when compared with wt littermates (Figure $4 A, C, G$ ). To further confirm, we performed Ki67 immunohistochemistry on cerebellar sections at P6, demonstrating the abundant presence of Ki67 immunopositive cells in the EGZ of wt mice, indicative of a proliferative environment (Figure 4E,H). Supporting our BrdU results, the number of proliferating (Ki67 positive) cells was markedly lower (to $\sim 25 \%$ ) in the nax cerebellum (Figure $4 \mathrm{~F}, \mathrm{H}$ ).

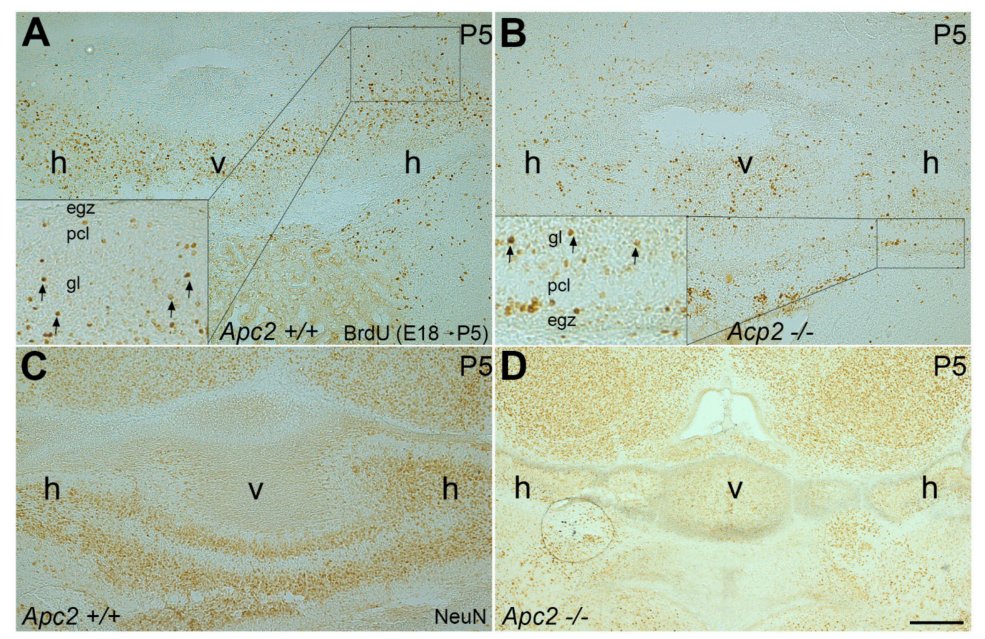

Figure 3. Visualization of BrdU incorporation in frontal sections at P5, following BrdU injection at E18 in timed pregnant mice. (A,B) BrdU staining shows that immunopositive cells migrate from EGZ to the GC layer (gl) in the wt (A) and nax (B) cerebellum, which is indicated by arrows in the inset. (C,D) NeuN immunostaining of serial sections of wt (C) and nax (D) cerebella confirming migration of mature GCs to the gl. Abbreviations: egz, external germinal zone; gl, granule cell layer; h, hemisphere; pcl, Purkinje cell layer; v, vemis. Scale bars: $200 \mu \mathrm{m}$ in (D) applies to (A-D).

\subsection{Is the SHH Signaling Pathway Impaired in the nax Cerebellum?}

The SHH signaling pathway is an important regulator of GC precursor proliferation during cerebellar development $[16,23,24]$. To determine whether the $\mathrm{SHH}$ pathway is impaired in nax mice and if this could underpin disrupted GC proliferation, section immunostaining and Western blotting were performed using wt and nax cerebella. PCs represent the primary source from which $\mathrm{SHH}$ is secreted. Immunostaining of P12 cerebellar sections revealed that nax PCs express $\mathrm{SHH}$ at levels comparable to those of wt PCs (Figure 5A,B; Supplementary Figure S2 (the secondary antibody control)). To precisely assess the dynamics of $\mathrm{SHH}$ protein expression over time, Western blotting was performed using samples harvested at P5, $-7,-10,-15$ and -19 from wt and nax cerebella. SHH protein levels peaked at P10-P15 in the wt mouse and declined thereafter (Figure 5C,D). Interestingly, in the nax cerebellum, SHH expression appears to increase beyond P10 and is maintained at high levels through P19 (Figure 5C,D). 


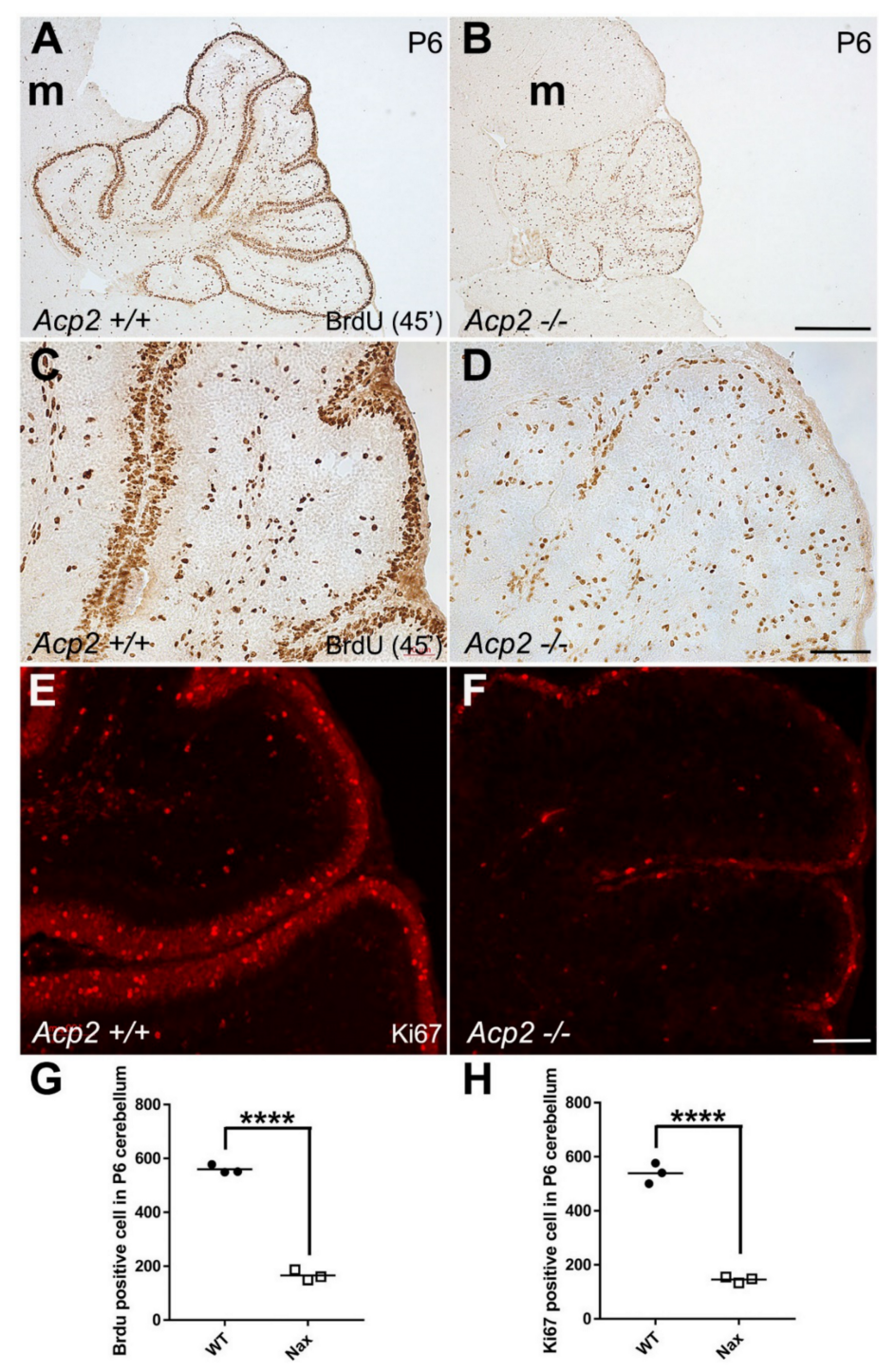

Figure 4. Using BrdU and ki67 to assess GC proliferative activity in wt and nax cerebella at P6. $(A-D, G)$ Visualization of BrdU incorporation in nax and wt cerebellar sagittal sections, 45 min after BrdU injection at P6. BrdU staining revealed a higher number of proliferating (immunopositive) cells in the EGZ in wt ((A), higher magnification in (C)) as compared to nax cerebellum $(\mathbf{B})$ and higher magnification in (D)). Number of proliferating cells in the EGZ that are BrdU immunopositive is significantly higher in wt than in nax littermates (wt; $n=3$ and nax; $n=3$ ). Quantitative analysis shows that the BrdU' index is about $30 \%$ in nax compared to wt. $(\mathbf{E}, \mathbf{F}, \mathbf{H}) \mathrm{Ki67}$ immunostaining of cerebellar sections confirmed that the number of proliferating cells in the EGZ is higher in wt (E) than in nax mice (D). Similar to the BrdU results, cell counting of sagittal sections at P6 shows a significant reduction in the number of Ki67 positive cells in the EGZ in the nax cerebellum than in wt littermates (wt; $n=3$ and nax; $n=3$ ). The data in the graph are presented as the mean $\pm \mathrm{SEM}$, and statistical analysis was performed using unpaired $t$-test $\left.{ }^{* * * *} p<0.0001\right)$. Abbreviation: $\mathrm{m}$, mesencephalon. Scale bars: $500 \mu \mathrm{m}$ in (B) applies to (A,B), $100 \mu \mathrm{m}$ in (D) applies to (C,D), $100 \mu \mathrm{m}$ in (F) applies to $(\mathbf{E}, \mathbf{F})$. 


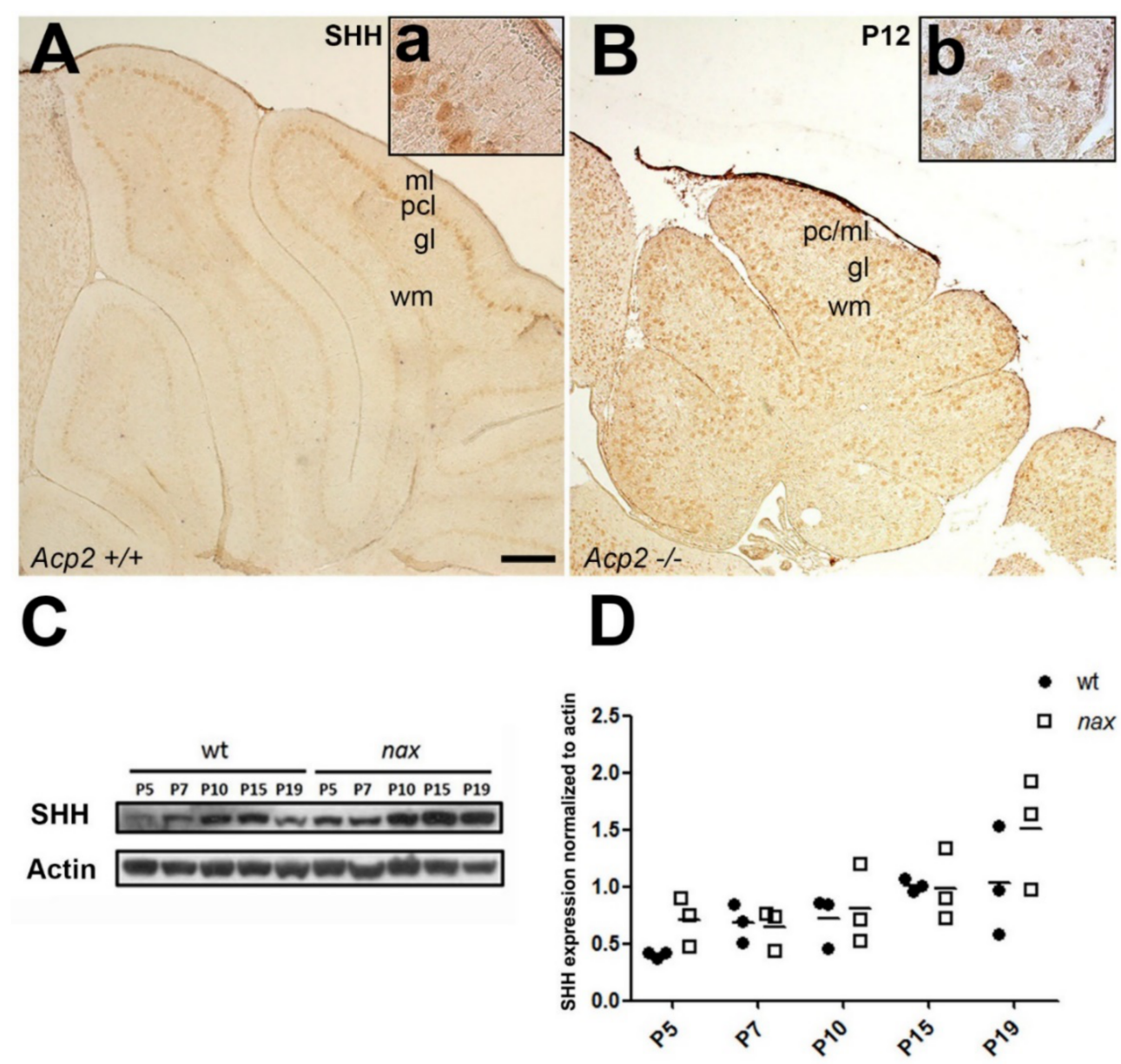

Figure 5. $\mathrm{SHH}$ is expressed to a similar extent by cerebellar PCs in wt and nax mutant mice. (A,B) Sagittal sections of P12 wt and nax mouse cerebella immunostained with SHH show that the expression of $\mathrm{SHH}$ is localized in PCs in both groups. (C,D) Western blot analysis of $\mathrm{SHH}$ expression at P5, $-7,-10,-15$ and -19 reveals a modest increase over time and similar expression levels in wt and nax cerebella at all time-points (wt: $n=3$ and nax: $n=3$ ). The actin shows consistent and equal loading of all cerebellar samples. The data in the graph are presented as the mean \pm SEM, and statistical analysis was performed using one-way ANOVA. Abbreviations: gl, GC layer; ML, molecular layer; PCL, PC layer; wm, white matter. Scale bars: $100 \mu \mathrm{m}$ in (A) applies to (A,B).

SHH signaling is regulated by multiple mechanisms and interactions with various proteins [46]. Extracellularly, the SHH signaling response and distribution are regulated by HHIP, CDON (Codon), BOC (Brother of Codon), and GAS1, which dynamically interact with the Patched 1 (receptor), leading to the controlled release of SMO inhibition [46]. RTqPCR showed that Hhip gene expression in the nax cerebellum was comparable to control levels at P5 and P10 (Figure 6A). At P15, however, an increase in Hhip gene expression was observed in $\mathrm{wt}$, whereas levels remained low and comparable to P5 and 10 in the nax cerebellum (Figure 6A). Ptch1 gene expression did not differ significantly from controls at any time-point (Figure 6B). 


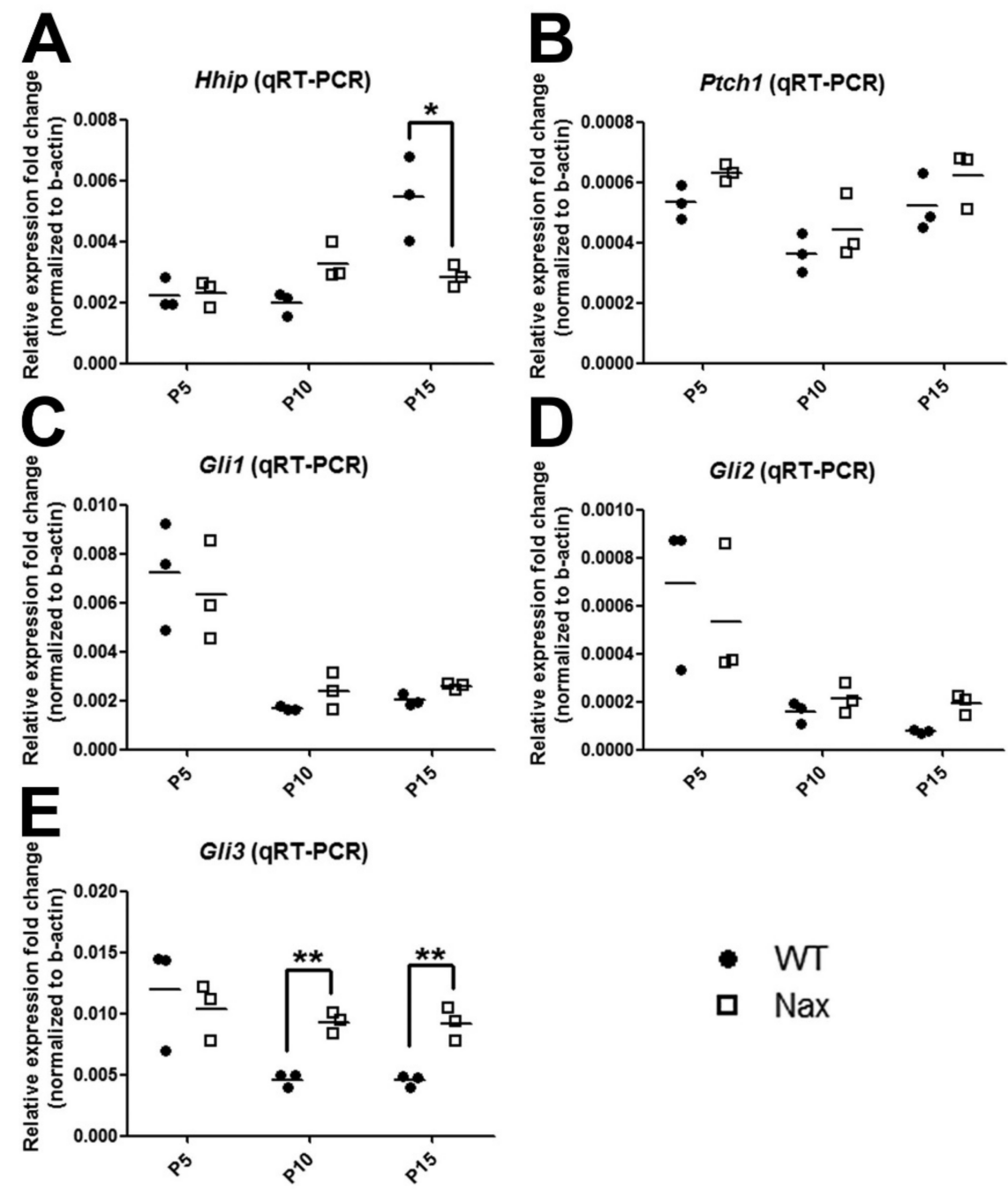

Figure 6. mRNA transcription levels of Hhip, Ptch1, and Gli1-3 in wt and nax cerebella. (A) Based on RT-qPCR, Hhip gene expression in wt and nax cerebella was comparable at P5 and P10, which are the most critical days for GC proliferation. In wt mice, expression appears to be increased at P15, whereas it remained at the same level in nax animals $\left({ }^{*} p<0.05\right.$ compared to $\left.w \mathrm{t}\right)$. (B) No differences in Ptch1 expression were observed between wt and nax cerebella; expression levels did not significantly change over time (P5-15). (C) As compared to P5, Gli1 gene expression decreased over time at P10 and 15; no significant differences were observed between the nax and wt cerebellum at any time point. (D) Gli2 mRNA expression decreased over time in a similar fashion as for Gli1; no significant differences in Gli2 expression were observed between the nax and wt cerebellum. (E) Gli3 mRNA expression decreased over time in the wt cerebellum, in a similar fashion as for Gli1 and -2, but was maintained high (same level as on P5) at P10 and 15 in the nax cerebella. Expression levels were significantly different between wt and nax at P10 (** $p<0.01)$ and $15(* *<0.01)$. The data in the graph are presented as the mean \pm SEM, and statistical analysis was performed using an unpaired $t$-test.

The GLI family of zinc finger transcription factors is a downstream nuclear effector of the SHH signaling pathway. GLI proteins participate in cell fate determination, proliferation and patterning of many cell types during embryonic development [25]. Gli1-3 expression was assessed by RT-qPCR in nax and wt littermate cerebella (Figure 6C-E). As compared to P5, Gli1 and -2 gene expression decreased over time at P10 and 15; no differences in Gli1 and Gli2 gene expression were observed between the nax and wt cerebella (Figure 6C,D). Gli3 mRNA expression also decreased in the wt, in a similar fashion as for Gli1 and -2, but remained at the same level as on P5 at P10 and 15 in nax cerebella (i.e., Gli3 expression was 
maintained, Figure 6E). As a result, expression levels were significantly different between wt and nax at P10 and 15. In addition, a heat map graphical analysis using RNAseq data sets from nax and wt cerebella at P5/P7 revealed that Shh signaling molecules are dysregulated in the nax cerebellum (Figure 7). For instance, Shh and its cofactors such as Scube are upregulated and Smo and Grk2 appear downregulated in nax mice.

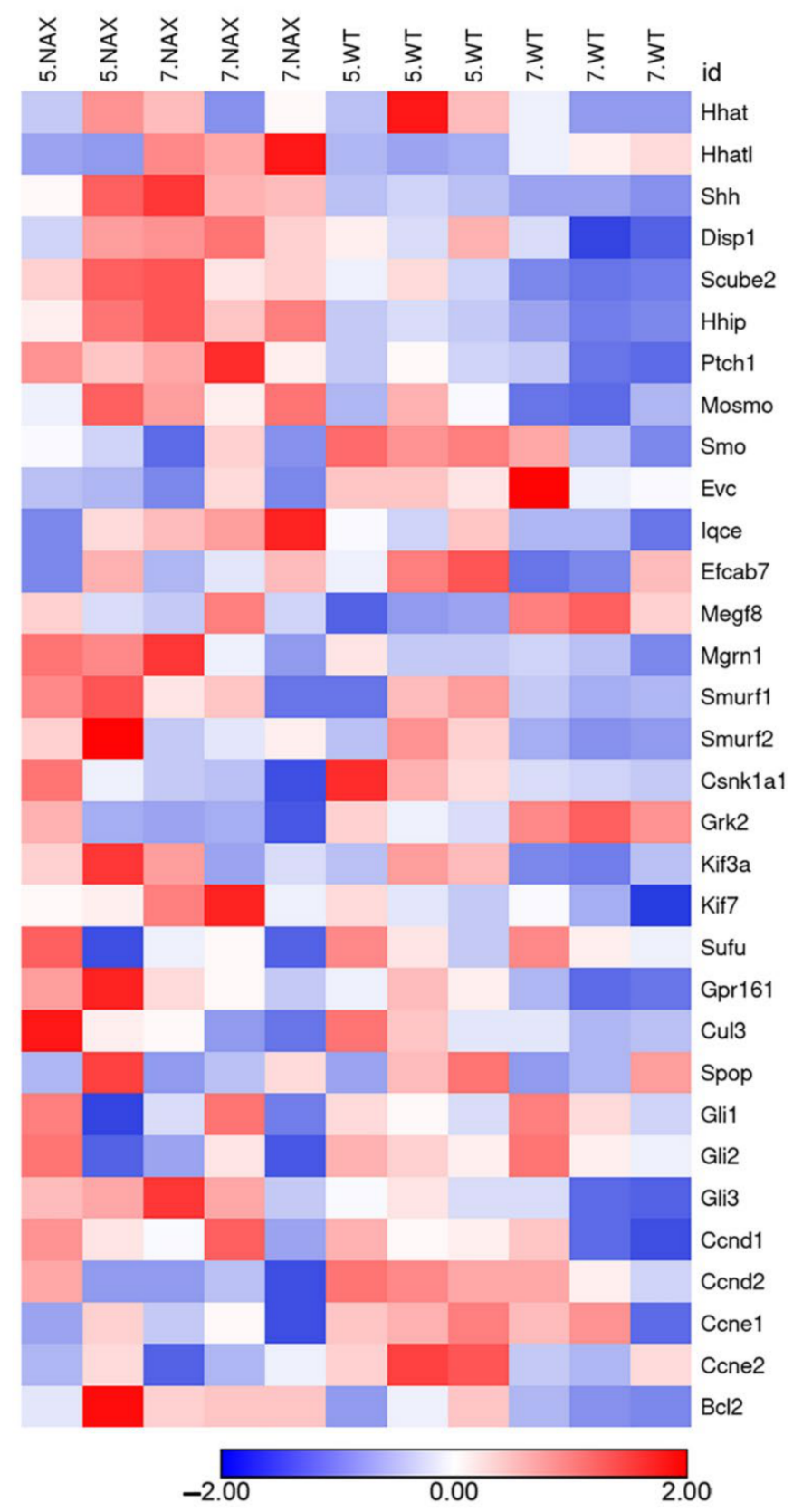

Figure 7. Heat map analysis of SHH pathway in the nax cerebellum at P5/P7. The rows of the heat map represent the genes of interest and the columns represent the experimental samples. Each cell is colored based on the level of expression of that gene in that sample. This heat map analysis shows color-coded expression levels of up (red)- and down (blue)-regulated genes. The data show that $\mathrm{SHH}$ signaling pathways are dysregulated in the nax cerebellum. 


\subsection{MYCN Expression Patterns Are Altered in the nax Cerebellum}

MYCN, a downstream target of the SHH pathway, is highly expressed in the embryonic brain and plays a vital role in development, especially regarding cerebellar GC precursor proliferation [29-31]. Nax and wt cerebellar sections were immunostained with an MYCN antibody at P5 and P12. Our results show that the protein localizes to GC precursors of the EGZ in both the wt (Figure 8A,C) and mutant (Figure 8B,D) and suggest a decreased immunoreactivity for MYCN in the nax cerebellum at P12 (Figure 8c, $\mathrm{c}^{\prime}$ vs. Figure $8 \mathrm{~d}, \mathrm{~d}^{\prime}$ ). MYCN protein levels (Figure 8E) typically increase from P5 to P10, as shown for the $\mathrm{wt}$, and subside towards the end of clonal expansion (P15). In the nax cerebellum, MYCN protein expression was comparable to wt at P5 but peaked earlier at P7 and then progressively decreased (Figure $8 \mathrm{E}$ ). Importantly, MYCN protein expression was significantly lower in the nax mutant at P10 and 15. Both immunohistochemistry and Western blotting results suggest that MYCN protein expression is markedly decreased after cerebellar GC precursor proliferation peaked in the nax cerebellum and is virtually absent at P15. Next, we asked if protein downregulation in the nax cerebellum was due to decreased Mycn gene expression. Based on RT-qPCR results, no differences were observed in Mycn gene expression between nax and wt cerebella. RNA expression gradually decreased at P10 and 15 as compared to P5 to a similar extent in both groups (Figure 8F).

The observed reduced MYCN protein abundance could be due to an increased protein degradation or decreased synthesis. MYCN is degraded via the ubiquitin-proteasome system, which is regulated by catalyzing the polyubiquitination and degradation of MYCN to balance the proliferation and differentiation in GCs [47,48]. The proteasome expression was explored by immunostaining wt and nax MEF cells $\left(\mathrm{MEF}^{\mathrm{wt}}\right.$ and $\mathrm{MEF}^{\text {nax }}$ ) with antiproteasome antibody. The proteasome immunoreactivity in both the nucleus and cytoplasm was apparently similar in $\mathrm{MEF}^{n a x}$ compared to $\mathrm{MEF}^{\mathrm{wt}}$ cells. However, the proteasome activity assay demonstrated that the proteasome activity in $\mathrm{MEF}^{\text {nax }}$ is significantly higher than in MEF ${ }^{\mathrm{wt}}$, which may imply the potential for accelerated clearance of proteins such as MYCN (Supplementary Figure S3). Further studies will be required to address this point.

It has been shown in MYCN-amplified neuroblastoma that the protein synthesis machinery is significantly upregulated [49]. A heat map graphical analysis using RNAseq data sets from nax and wt cerebella revealed that gene expression of both large (Figure 9A) and small (Figure 9B) subunits of the ribosomal proteins are strongly downregulated in the nax cerebellum. Of note, this observation might be associated with the strongly reduced number of GCs in the nax cerebellum. 

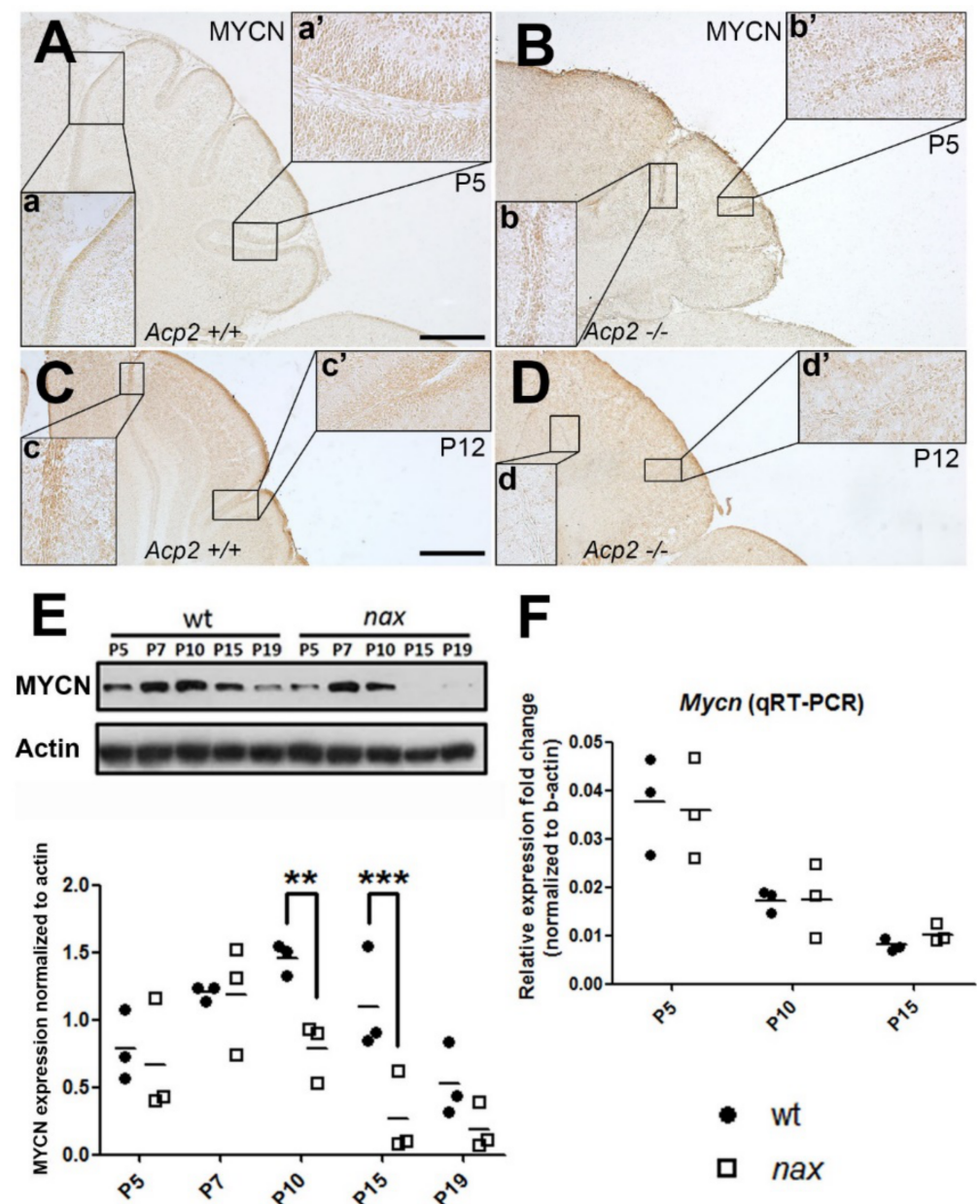

Figure 8. MYCN is expressed by GC precursors in wt and nax cerebella, but cerebellar MYCN protein levels are lower in the nax mutant mouse at P10 and P15. (A,B) Sagittal sections of P5 wt and nax mutant mouse cerebella immunostained with MYCN show expression in GC precursors. Higher magnifications of the wt $(\mathbf{A})$ and $\operatorname{nax}(\mathbf{B})$ anterior $(\mathbf{a}, \mathbf{b})$ and posterior $\left(\mathbf{a}^{\prime}, \mathbf{b}^{\prime}\right)$ lobes are shown in the inserted panels. (C,D) Sagittal section of P12 nax mutant mouse cerebellum (D) immunostained with MYCN shows lower expression in GC precursors compared with wt littermates (C). Higher magnifications of the wt (C) and nax (D) anterior $(\mathbf{c}, \mathbf{d})$ and posterior $\left(\mathbf{c}^{\prime}, \mathbf{d}^{\prime}\right)$ lobes are shown in the inserts. (E) Western blot analysis of MYCN expression in wt and nax cerebellar lysates at P5, -7, -10, -15 and -19 (wt: $n=3$ and nax: $n=3$ ). In the wt samples, MYCN protein levels increased from P5 to P10 and subsided towards the end of clonal expansion (P15). In the nax cerebellum, MYCN protein expression was comparable to wt at P5, but peaked earlier at P7 and then progressively decreased. Importantly, expression was significantly lower in the nax mutant at P10 and P15. The actin shows consistent and equal loading of all cerebellar samples. The scatter plots show individual data points and statistical analysis was performed using one-way ANOVA ${ }^{* *} p<0.01$ and $\left.{ }^{* *} p<0.001\right)$. (F) Cerebellar Mycn mRNA expression gradually decreased at P10 and 15 as compared to P5 to a similar extent in both nax and wt mice. No significant differences in Mycn expression were observed between the groups at any time point. $\beta$-actin gene expression was used to normalize the qRT-PCR data. The data in the graph are presented as the mean \pm SEM, and statistical analysis was performed using an unpaired $t$-test. Scale bars: $500 \mu \mathrm{m}$ in (A applies to $(\mathbf{A}, \mathbf{B})$ and $500 \mu \mathrm{m}$ in (C applies to (C,D). 


\section{A}

xxyx

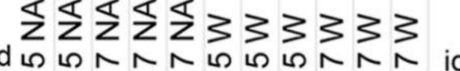

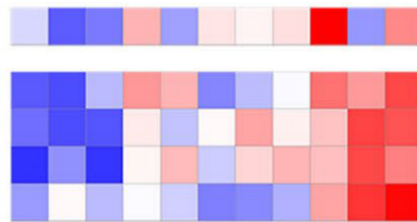

Rpl10

Rpl10a

Rpl9

Rpl12

Rpl24
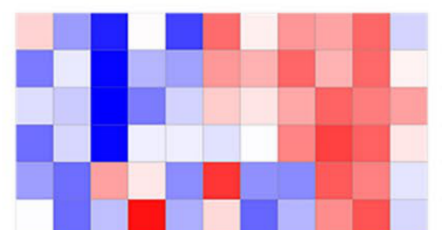

Rpl4

Rpl7

Rpl18a

Rplp2

Rpl27

Rpl7a

Rpl23

Rpl14

Rpl26

Rpl8

Rpl32

Rplp0

Rpl18

Rpl29

Rpl36

Rpl19

Rpl21

Rpl37a

Rpl28

Rpl13

Rpl39

Rpl41

Rplp1

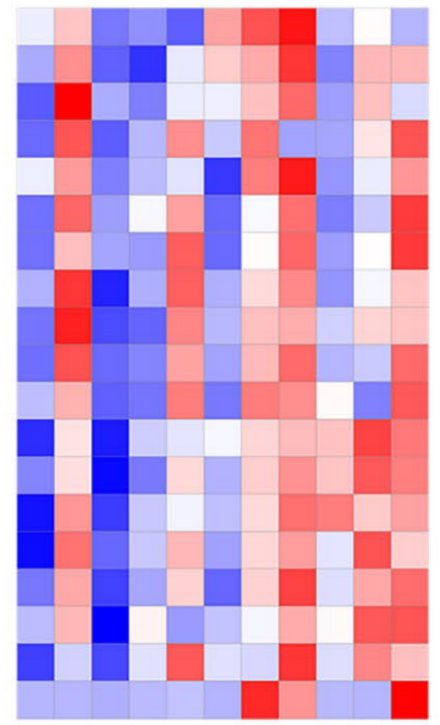

Rpl3

Rpl6

Rpl15

Rpl11

Rpl23a

Rpl5

Rpl38

Rpl22

Rpl36a

Rpl35

Rpl30

Rpl13a

Rpl17

Rpl31

Rpl27a

Rpl37

Uba52

Rpl35a

Rpl34

\section{xجx}

过过过33333

id

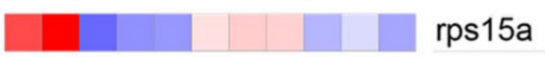

+

rps10

rps12

$\operatorname{rps} 4 \mathrm{x}$

rps5

rps9

rps11

rps8

rps15

rps20

rps3

rps21

rps24

rps19

rps13

rps7

rps14

rpsa

rps3a1

rps16

fau

rack1
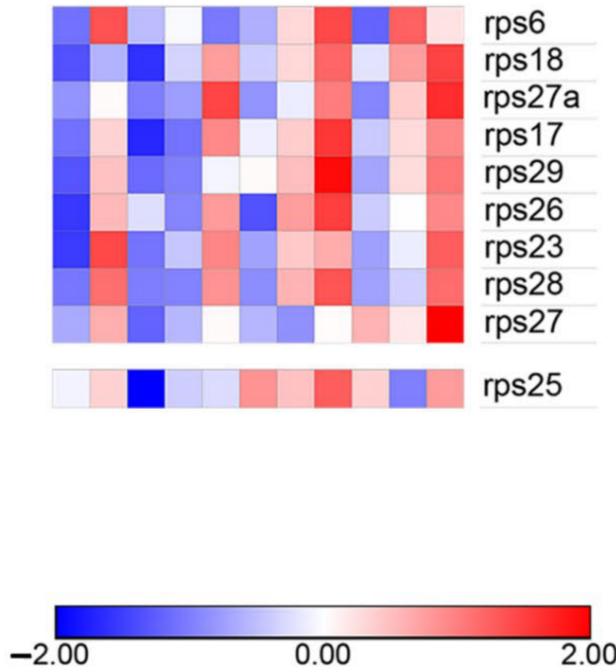

\section{dendrogram cut}

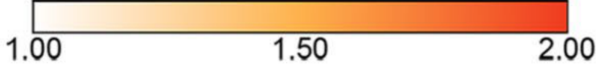

Figure 9. Heat map analysis of ribosomal protein gene expression in the nax cerebellum at P5/P7. The rows of the heat map represent the genes of interest and the columns represent the experimental samples. Each cell is colored based on the level of expression of that gene in that sample. This heat map analysis shows color-coded expression levels of up (red)- and down (blue)-regulated genes. The data show that major clusters of genes coding for large (RPL), (A) and small ribosomal subunits (RPS), (B) are markedly downregulated in the nax cerebellum. 


\section{Discussion}

GCs constitute the largest neuronal population of the CNS. These neurons are significantly decreased in number in the nax cerebellar cortex (around $20 \%$ of that in wt controls). SHH signaling is important in the development of the GC precursors in the EGZ. SHH releases the inhibition of SMO by inducing a conformational change in the PTCH1. Derepressed SMO then activates the GLI factors and targets MYCN as well as cyclins, which drive GC clonal expansion in the EGZ [31].

In the present study, we describe the effects of the Acp2 gene mutation on GC proliferation observed in the nax cerebellum. The total number of GCs is strongly reduced in the nax cerebellum, and PAX6 immunopositive GC precursors of the EGZ are dramatically decreased in number as well-particularly in the vermis-at P6, corresponding to the peak of GC precursor proliferation (Figure 2E,H,I). Because GCs rely on SHH signaling for their clonal expansion, we examined the expression levels of $\mathrm{SHH}$ as well as various other molecules involved in its signaling cascade as effectors or modulators during GC precursor proliferation in the EGZ. Our results indicate that SHH protein levels moderately increase over time (P5-19) and are comparable between PCs from nax and wt littermates. An increase in Hhip gene expression was observed in wt at P15, whereas levels remained low and comparable to P5 and 10 in the nax cerebellum. No relevant changes in comparison to wt controls were observed in the expression of mRNAs encoding the SHH receptor Ptch1 and the nuclear transducer Gli1. Interestingly, however, while no differential expression is detected in the levels of the Mycn transcript, the abundance of MYCN protein in whole cerebellar lysates is significantly lower in nax mice at P10 and, expectedly, remains much lower than in the wt animals at later stages (P15-19), given the low number of GCs in the nax cerebellum.

Despite abundant neuronal degeneration in the nax cerebellum [39], it seems that the reduced number of GCs is due to the decreased proliferative activity of GC precursors during development (Figure 4). Numerous in vitro and in vivo studies have indicated that $\mathrm{SHH}$ is the primary mitogen that regulates the proliferation of GC precursors in the EGZ $[16,18,21,50,51]$, and that SHH malfunction leads to reduced proliferative activity of the GC precursors $[18,51,52]$. After secretion by PCs, the effects of SHH on transcription factor GLIs in the target cells, in this case GCs, are co-regulated by Hhip, Ptch1, and Smo. A significantly lower cerebellar Hhip (HHIP is an SHH inhibitor) mRNA expression was observed in nax mice at P15, a stage where there is a decline in GC proliferation and clonal expansion is almost complete. How this paradoxical finding translates to HHIP protein expression and function needs to be further elucidated. It could be that because proliferation is already suppressed in the nax mouse, and fine-tuning inhibitory mechanisms that would result in an even larger reduction in proliferation, like those mediated by Hhip, are not being employed. Alternatively, HHIP expression has been suggested to be a readout of Shh signal transduction, like Ptc1 [53], and lower HHIP expression might therefore simply reflect decreased signaling, which is congruent with increased expression of the negative transducer in the pathway (i.e., Gli3) at these stages.

One of the readouts of SHH signaling pathway activity is transcription factor GLI1/2; from P5 to P15, Gli1 and -2 mRNA levels decreased and expression was comparable in the nax and wt cerebellar cortex at all time-points. Since the proportion of GCs is much smaller in the mutant, it is conceivable that individual GCs in the nax cerebellum express higher levels of Gli1/2, which would "compensate" for reduced cell number. Alternatively, Gli1/2 expression in Bergmann glial cells may also compensate for reduced expression in GCs, or it could be postulated that even though the number of total GCs is decreased in the nax cerebellum, this is proportionate to the size of the tissue, and that the consistent Gli1/2 expression indicates that GCs present in the nax cerebellum go through a relatively normal life. GLI1 belongs to the GLI family and participates in many cellular activities, such as cell proliferation and cell fate determination [24,25]. In the cerebellum, GLI1 is an important protein in GC precursor proliferation; as indicated, expression of Gli1 and 2 was similar in the nax and wt cerebellum. Whereas Gli3 mRNA levels decrease from P5 to P15 in the 
wt cerebellum, in a similar fashion as for Gli1 and -2, Gli3 expression (likely reflecting the PC layer) remains constant and is significantly higher at P10 and 15 in the nax cerebellum. It has been shown that in the absence of SHH signal, GLI3 converts to a repressor form and acts as a major negative transducer of the pathway [54]. Moreover, Gli3 expression is required for the Wnt-dependent negative regulation of $\mathrm{SHH}$ and control of cell proliferation and differentiation postnatally [55-57], and Wnt3 inhibits cerebellar GC proliferation [58], probably through Gli3. Importantly, ablation of GLI3 in Shh knockout mice restored the expression of several genes, including Mycn [59]. The sustained postnatal expression of Gli3 after clonal expansion might represent a potential mechanism contributing to the reduced number of GCs in the nax cerebellum other than the SHH pathway.

Mycn gene expression was not significantly different in the nax cerebellum compared to wt littermate controls at any of the time-points studied. MYCN is an essential downstream effector of SHH signaling mediated by GLI during both normal and neoplastic cerebellar growth and is associated with GC precursor proliferation [31]. The Mycn gene is found amplified repeatedly in metastatic human neuroblastomas and serves as a transcription factor that participates in many cellular processes, including proliferation, differentiation, and apoptosis [31,60-63]. Impaired Mycn expression has been shown to disturb cerebellar development in mice as evidenced by a small size, disorganized and damaged foliation, and an 8-fold reduction of GC precursors compared with the control group [30]. In addition, in vitro and in vivo studies have demonstrated that $\mathrm{Mycn}$ is directly induced by $\mathrm{SHH}$ and that MYCN is required for GC precursor proliferation and plays a central role in SHH-mediated proliferation and tumorigenesis $[31,64]$.

In contrast to Mycn gene expression, Western blot analysis showed that MYCN protein abundance is significantly decreased in the nax cerebellum; of note, this reflects protein expression after the clonal expansion peak. Proteasomal degradation of polyubiquitinated MYCN protein has been described $[47,65]$. Endogenous MYCN binds to ligases, such as HUWE1, prior to degradation by the proteasome [47]. Due to this degradation, MYCN is a short-lived protein with a half-life of only 30 min [5,31,61]. Degradation of MYCN withdraws the cells from proliferation and initiates their differentiation [47,65]. We observed preliminary evidence of increased proteasome activity in $\mathrm{MEF}^{\text {nax }}$ cells. These findings suggest that in these fibroblasts grown from nax embryos, proteasome activity is increased, leading to augmented degradation of $\mathrm{MYCN}$, which possibly explains reduced (GC) proliferation at a later stage of postnatal development. It is important to mention that in addition to proteasome impairment, it is conceivable that disruptions in processes such as cell recycling, autophagy, and responses to cellular stress contribute to our observations. Recently, we showed that the defect of lysosomal protein degradation in nax animals may be due to a malfunction in lysosomal activity. Thus, it is possible that our observed mismatch between gene and protein expression is associated with defect(s) of the proteasome system, autophagy, and/or lysosomal protein degradation in the nax model [66].

The observed alterations in the SHH-MYCN pathway in nax mice are preceded by a significant reduction in GCs during clonal expansion. At the peak of the clonal expansion, we observed Shh signaling pathway dysregulation. For instance, ligands (Shh and cofactors) are upregulated. and Smo and Grk2, key substrates and modulators of Shh signaling, are downregulated, in keeping with observations made by Zhao et al. [67]. Therefore, this evidence may suggest a likely upregulation of extracellular ligands due to disrupted Shh signals transduction, and a possible consequence is decreased MYCN expression.

In addition, we have observed a downregulation of ribosomal protein gene expression in the nax cerebellum. MYCN is known to enhance the expression of a large set of genes functioning in ribosome biogenesis and protein synthesis [49]. While the GC proliferation defect may stem from downregulation of ribosomal protein expression, further investigation is required to assess the causal relationships between the two events in purified GCs.

Cerebellar developmental tumors such as medulloblastoma are among the most common malignant pediatric brain tumors that originate from cerebellar GC precursor cells due 
to impairment of several molecular pathways, including $\mathrm{SHH}$ and $\mathrm{MycN}[48,68-70]$. Our observations may pave the way for pharmacologic manipulation of Acp 2 as an approach of cerebellar developmental disorders such as the SHH group of medulloblastomas and Group 3 tumors and MYC signaling.

\section{Materials and Methods}

\subsection{Animal Model}

All animal procedures described in this study were performed in accordance with institutional regulations and the Guide to the Care and Use of Experimental Animals from the Canadian Council for Animal Care and have been approved by local authorities "the Bannatyne Campus Animal Care Committee", University of Manitoba (approved protocol \# 15066).

A nax mutant colony was established in the Genetic Modeling Center at the Faculty of Health Sciences, University of Manitoba, after the embryos were obtained from the Institute of Human Genetics at the University Medical Center, Georg-August University, Göttingen, Germany. The line was backcrossed with C57BL/ 6 breeders to maintain the nax mutation on a pure genetic background. The animals were kept at room temperature and relative humidity $\left(18-20^{\circ} \mathrm{C}, 50-60 \%\right)$ on a $12 \mathrm{hrs}$ light-dark cycle. In this study, a total of 78 mice were used. After anesthesia (40\% isoflurane, USP (Baxter Co., Mississauga, ON, Canada)), brains were removed and fixed in $4 \%$ paraformaldehyde (PFA) for immunohistochemistry (IHC) or prepared for Western blotting and real-time quantitative PCR.

\subsection{Genotyping}

The nax mouse can be phenotypically distinguished from wild type (wt) littermates by appearance (small size, lack of body hair, and ataxia). In order to confirm the genotypes, we performed PCR using the following primers: Acp4F (5' GCACTCTGTGCCTTCTCCAT$\left.3^{\prime}\right)$ and Acp4R (5'-CTGGGAGATTTGGGCAACTA-3'). After cleaving with the BamHI restriction enzyme type II at $37^{\circ} \mathrm{C}$ for $2 \mathrm{hrs}$, the DNA samples were loaded on a $2.5 \%$ agarose gel prepared in $0.5 \times$ TBE buffer with $1 \mu \mathrm{g} / \mathrm{mL}$ ethidium bromide. A single $525 \mathrm{bp}$ band identified the homozygous genotype; two bands (320 and $200 \mathrm{bp}$ ) identified the wild type genotype; three bands of 525, 320, and 200 bp identified the heterozygous genotype.

\subsection{Cryosection}

Whole brains were obtained from wt and nax mice and fixed overnight in $4 \%$ paraformaldehyde (PFA) at $4{ }^{\circ} \mathrm{C}$. Next, PFA was replaced by sequential 10, 20, and 30\% sucrose and kept overnight at $4{ }^{\circ} \mathrm{C}$. The cerebellum was embedded in OCT compound and cryostat sectioned at $20 \mu \mathrm{m}$ and processed for immunohistochemistry according to our laboratory SOPs (e.g., [71]).

\subsection{Immunohistochemistry}

For immunohistochemistry (IHC), we used our standard lab protocol, as previously published [38,39]. Briefly, the sections were washed with PBS and treated with $0.3 \% \mathrm{H}_{2} \mathrm{O}_{2}$ to stop the endogenous peroxidase activity, followed by another wash. Sections were kept in blocking solution (10\% normal goat serum and 0.05\% Triton $\mathrm{x}-100$ in PBS) for $1 \mathrm{~h}$ and subsequently incubated overnight at room temperature with primary antibody (anti-NeuN rabbit polyclonal, Millipore Sigma, Oakville, ON, Canada, 1:1000 [72]; anti-PAX6 mouse monoclonal, Developmental Studies Hybridoma Bank [73], 1:25; anti-calbindin D-28K mouse monoclonal, Swant, 1:1000 [39]; anti-sonic hedgehog rabbit polyclonal, Millipore Sigma, 1:200 [19]; anti-MYCN mouse monoclonal, Millipore Sigma, 1:25 [74], anti-proteasome $20 \mathrm{~S}$ alpha + beta rabbit polyclonal, Abcam, Toronto, ON, Canada, 1:400, and anti-GFAP rabbit polyclonal (Millipore Sigma, 1:1000). After thorough washing with PBS, sections were treated for $2 \mathrm{~h}$ with the appropriate secondary antibody (goat anti mouse IgG, HRP conjugate, Millipore Sigma, 1:500; goat anti rabbit IgG, HRP conjugate, Millipore Sigma, 1:500). Diaminobenzidine (DAB) was used as a chromogen. For immunofluorescence 
staining, the secondary antibodies were Alexa Fluor 488 goat anti-mouse or anti-rabbit IgG and Alexa Fluor 594 goat anti-rabbit or anti-mouse IgG (Thermo Fisher, Ottawa, ON, Canada, 1:1000). For autofluorescence control, the primary antibody was omitted.

\subsection{Bromodeoxyuridine (BrdU) Incorporation Assay}

BrdU (Sigma, Aldrich, Oakville, ON, Canada, Cat\# 59-14-3) was dissolved in $0.007 \mathrm{~N}$ $\mathrm{NaOH}+0.9 \% \mathrm{NaCl}$. At a dosage of $50 \mathrm{mg} / \mathrm{kg}$ body weight $(\sim 100 \mu \mathrm{L})$, BrdU solution was injected intraperitoneally to timed pregnant mice at E18 and pups were perfused at P5, or pups were injected postnatally at P6 and perfused after $45 \mathrm{~min}$. The brain was removed and cryostat cerebellar sections were subjected to IHC using mouse monoclonal anti-BrdU (Sigma, Cat\# B8434, 1:500).

\subsection{Western Blotting}

Cerebellum samples were collected from nax mutants and wt littermates at different ages (P5, -7, -10, -15, and -19). The samples were placed in lysis buffer containing a protease inhibitor cocktail (Life Science, Peterborough, ON, Canada, Cat\# M250) and phosphatase inhibitor (Sigma Aldrich, Oakville, ON, Canada, Cat\# P5726). After sonication of the samples, protein concentrations were determined using a BCA protein assay kit (Bio-Rad, Mississauga, ON, Canada, Cat\# 5000121). Protein samples were suspended in loading buffer (Tris- $\mathrm{HCl} 60 \mathrm{mM}$, glycerol 25\%, SDS 2\%, mercaptoethanol (ME) $14.4 \mathrm{mM}$, bromophenol blue $\left.0.1 \%, \mathrm{H}_{2} \mathrm{O}\right)$, and equal amounts of total protein $(12 \mu \mathrm{L}$ of each sample was loaded, $5 \mu \mathrm{L}$ precision plus protein was used as marker standard (Thermo Fischer Scientific, ON, Canada)) were separated by sodium dodecyl sulfate polyacrylamide gel electrophoresis; based on the molecular weight of the protein of interest, $6-15 \%$ polyacrylamide gels were used. After separation, proteins were transferred to a polyvinylidene fluoride membrane. The membrane was blocked with $5 \%$ milk and incubated with primary antibody (Anti-Sonic hedgehog Rabbit Polyclonal, Millipore Sigma, 1:400; Anti-MYCN Mouse Monoclonal, Millipore Sigma, 1:200; in 1× TBST (Tris-buffered saline/0.01\% tween 20) overnight at $4{ }^{\circ} \mathrm{C}$, then washed 3 times with $1 \times$ TBST for 20 min each time and incubated with secondary antibody (goat anti mouse IgG, HRP conjugate, Millipore Sigma, 1:5000; goat anti rabbit IgG, HRP conjugate, Millipore Sigma, 1:5000) in 1× TBST for $2 \mathrm{~h}$. Membranes were washed 3 times for 20 min with $1 \times$ TBST, and the immunoreactive bands were visualized by electrochemiluminescence (ECL) (Pierce, ON, Canada). The data were analyzed by AlphaEase software, and bands were normalized to $\beta$-actin expression.

\subsection{RNA Isolation and Analyses}

The cerebella of $\operatorname{nax}(\mathrm{P} 5 ; n=2$ and P7; $n=3$ ) and wt littermates (P5; $n=3$ and P7; $n=3$ ) were isolated and total RNA was extracted with the RNeasy Plus Mini Kit (Cat\# 74134, QIAGEN, Toronto, ON, Canada). RNA product concentration was measured by Nano-Drop ND-1000 UV-Vis Spectrophotometer (Thermo Fisher Scientific, Waltham, MA, USA). The samples were kept at $-80^{\circ} \mathrm{C}$ and sent to the McGill University and Genome Quebec Innovation Centre (MUGQIC). Raw RNAseq data were analyzed with FASTQ, and files were filtered and trimmed using the fastp package [75]. Next, cleaned data were aligned with the mouse reference genome (GRCm38.97) using Subjunc Aligner (v. 1.3.1) [76]; low-quality alignments, duplicates, and non-aligned sequences were removed from the aligned files using Samtools [77]. Finally, reads associated with each gene on the reference genome were extracted and counted using FeatureCounts software [78] and the "Reads Per Kilobase of transcript, per Million mapped reads" (RPKM) was calculated for each gene.

\subsection{Gene Expression Analyses}

Total RNA was extracted using a TRIzol ${ }^{\circledR}$ Plus RNA Purification kit (Life Technologies, Grand Island, NY, USA) according to manufacturer's instructions. RNA quality and quantity were assessed by measuring the absorbance at 260 and $280 \mathrm{~nm}$ using a NanoDrop ND-1000 UV-Vis Spectrophotometer (Thermo Fisher Scientific, Waltham, MA, USA). All 
samples had an absorption ratio A260/A280 between 1.8 and 2.2. One microgram of RNA from each sample was treated with RQ1 RNase-Free DNase ${ }^{\circledR}$ (Promega Corporation, Madison, WI, USA) to remove genomic DNA contamination, and reverse transcription was performed using SuperScript VILO cDNA Synthesis Master Mix (Invitrogen, Grand Island, NY, USA) according to manufacturer's recommendations. Real-time quantitative PCR (RT-qPCR) reactions were performed in a Roche LightCycler 96 Real-Time System using Power SYBR green master mix (Life Technologies) in a final reaction volume of $20 \mu \mathrm{L}$; all samples were tested in triplicate. The stability of the housekeeping gene TATA Box binding protein $(\mathrm{Tbp})$ was assessed as described previously $[79,80]$. Differences in the threshold cycle $(\Delta \mathrm{Ct})$ number between the target genes and TATA Box binding protein $(\mathrm{Tb} p)$ were used to calculate differences in expression.

\subsection{Mouse Embryonic Fibroblast (MEF) Culture}

Embryos were obtained from a heterozygous pregnant mouse. The tail was used for PCR to distinguish the genotype. The body was first minced and then digested with 0.25\% Trypsin/EDTA (Gibco, Burlington, ON, Canada, Cat\# 15090-046). After centrifuging the sample, the supernatant was discarded. The pellet was resuspended and added to a coated plate $(0.1 \%$ Gelatin solution) and incubated with MEF medium ( $10 \%$ fetal bovine serum, 1\% $200 \mathrm{mM}$ L-glutamine, and 1\% Penicillin-streptomycin in high glucose DMEM) at $37{ }^{\circ} \mathrm{C}$ and $5 \% \mathrm{CO}_{2}$ until cells reached $100 \%$ confluency. The cells were immortalized with SV40 $\mathrm{T}$ antigen and then frozen and stored in liquid nitrogen. The MEF cells from wt $\left(\mathrm{MEF}^{\mathrm{wt}}\right)$ and nax $\left(\mathrm{MEF}^{\text {nax }}\right)$ were collected, experimentally treated (if so required), and used for immunostaining, Western blotting, and proteasome activity assays.

\subsection{Proteasome Activity Assay}

To analyze $26 \mathrm{~S}$ proteasome activity in MEF cells, we measured the proteolytic activity of $20 \mathrm{~S}$ and the deubiquitinating activity of $19 \mathrm{~S}$ using fluorescent substrates. For more detailed information, refer to recent publications by Abu-El-Rub et al., 2019 and 2020 [81,82]. Briefly, $100 \mu \mathrm{L}$ of the Proteasome Lysis Buffer (Cayman chemical, Ann Arbor, Michigan, USA, Item No. 10011097) was added to MEF cells, followed by incubation with gentle shaking for $30 \mathrm{~min}$ at room temperature. After centrifugation, $90 \mu \mathrm{L}$ of supernatant from each sample was transferred to a black 96-well plate, followed by the addition of $10 \mu \mathrm{L}$ of SUC-LLVY-AMC proteasome substrate (Cayman chemical Item No. 10011095) and $10 \mu \mathrm{L}$ $26 \mathrm{~S}$ assay buffer. The fluorescent intensity was assessed to determine $20 \mathrm{~S}$ subunit proteolytic activity, after $1 \mathrm{~h}$ of incubation in the dark (excitation $=360 \mathrm{~nm}$; emission $=480 \mathrm{~nm}$ ). The deubiquitinating activity of $19 \mathrm{~S}$ was measured by transferring $90 \mu \mathrm{L}$ of each sample to a 96-well black plate, and $0.5 \mu \mathrm{L}$ of the Ubiquitin-Rhodamine 110 (Boston Biochem Item, Toronto, ON, Canada, Cat\# U-555) proteasome substrate solution and $10 \mu \mathrm{L}$ of $26 \mathrm{~S}$ assay buffer was added to each sample; the fluorescent intensity for 19S subunit activity was measured immediately after $1 \mathrm{~h}$ (excitation $=485 \mathrm{~nm}$; emission $=535 \mathrm{~nm})$.

\subsection{Imaging}

A Zeiss Axio Imager M2 microscope (Zeiss, Toronto, ON, Canada) was used to capture bright field images, which were analyzed with Zeiss Microscope Software (Zen Image Analysis software; Zeiss, Toronto, ON, Canada). Fluorescent images were captured by Zeiss Z1 and Z2 Imagers and a Zeiss LSM 700 confocal microscope (Zeiss, Toronto, ON, Canada). Adobe Photoshop CS5 was used to edit, crop, and finalize the images for presentation.

\subsection{Cell Counting}

Cerebellar GCs in the granular layer and GC precursors in the external germinal zone were counted using ImageJ software. Three slides were counted for each wt and nax cerebellum. Three sections were counted on each slide based on the standard size field $(950 \mu \mathrm{m} \times 715 \mu \mathrm{m})$. 


\subsection{Statistical Analysis}

GraphPad Prism 6 was used to evaluate the statistical significance of differences by analysis of variance (ANOVA) for more than two groups and student $t$-test for comparison of two groups. Differences were considered to be statistically significant when $p<0.05$ (level of significance is indicated in the figures $\left({ }^{*} p<0.05,{ }^{* *} p<0.01\right)$ ).

\section{Conclusions}

SHH-MYCN signaling has been shown to promote the proliferation of GC precursors in the cerebellum. In the cerebella of nax mice, the number of GCs and GC precursors amount to only $\sim 20 \%$ of that in the wt littermates. In this study, we showed that cerebellar MYCN protein expression is markedly reduced in nax mice at around P10, while Mycn gene expression remains unchanged. Upstream, the observed sustained postnatal expression of Gli3 in nax cerebella might affect SHH signaling, as it is also almost aligned with the temporal pattern of changes in MYCN expression. At the peak of GC proliferative activity, Shh signaling pathway is dysregulated and the ribosomal protein gene expression is reduced in the nax cerebellum, suggesting an impairment in other molecules associated with GC proliferation. Additional mechanisms regulating GC development during the clonal expansion period are likely impaired and warrant further investigation.

Supplementary Materials: The following are available online at https:/ / www.mdpi.com/1422-006 7/22/6/2994/s1.

Author Contributions: H.M. Designed the research and experiments, supervised the research, and wrote the paper. X.J., M.R.B., E.A.-E.-R., F.C., H.P.M., S.D., J.K., G.G.C. and H.M. analyzed data and co-wrote the paper. X.J., M.R.B., E.A.-E.-R., F.C. and H.P.M. performed experiments. All authors have read and agreed to the published version of the manuscript.

Funding: This research was funded by grants from the Natural Sciences and Engineering Research Council (HM: NSERC Discovery Grant \# RGPIN-2018-06040), The Children's Hospital Research Institute of Manitoba (HM: CHRIM Grant \# 320035), and Research Manitoba Tri-Council Bridge Funding Program (HM: Grant \# 47955).

Institutional Review Board Statement: The study was conducted according to the guidelines of the institutional regulations and the Guide to the Care and Use of Experimental Animals from the Canadian Council for Animal Care, and approved by local authorities "the Bannatyne Campus Animal Care Committee", University of Manitoba (approved protocol \# 15066; 2017).

Informed Consent Statement: Not applicable.

Data Availability Statement: Data is contained within the article or Supplementary Materials.

Acknowledgments: The authors would like to acknowledge Science Impact (Winnipeg, Canada) for (post-)editing the manuscript.

Conflicts of Interest: The authors declare no conflict of interest.

\section{Abbreviations}

$\begin{array}{ll}\text { Acp2 } & \text { Lysosomal acid phosphatase } 2 \\ \text { BOC } & \text { Brother of Codon } \\ \text { CDON } & \text { Codon } \\ \text { CNS } & \text { central nervous system } \\ \text { DAB } & \text { diaminobenzidine } \\ \text { E } & \text { embryonic day } \\ \text { EGL } & \text { external granule cell layer } \\ \text { EGZ } & \text { external germinal zone }\end{array}$




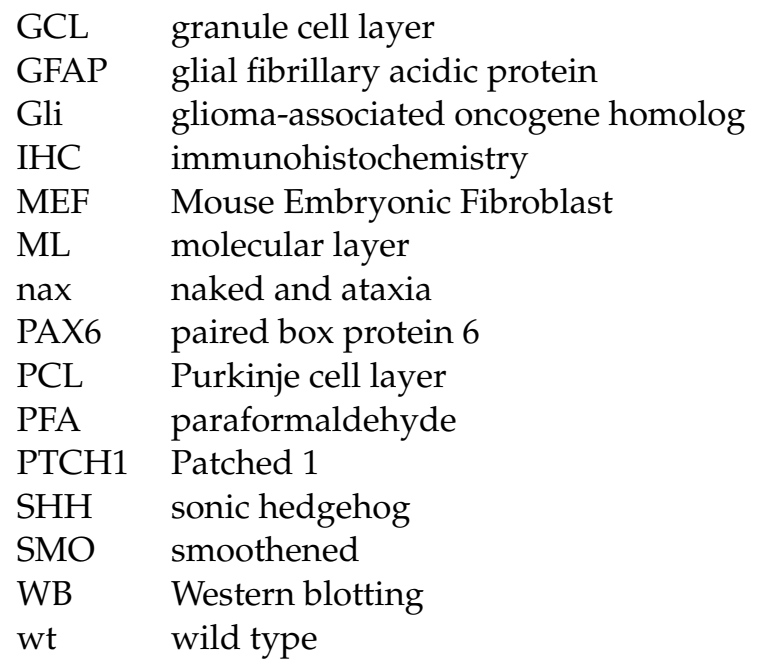

\section{References}

1. Steinlin, M. Cerebellar Disorders in Childhood: Cognitive Problems. Cerebellum 2008, 7, 607-610. [CrossRef]

2. Thach, W.T. On the mechanism of cerebellar contributions to cognition. Cerebellum 2007, 6, 163-167. [CrossRef]

3. Wolf, U.; Rapoport, M.J.; Schweizer, T.A. Evaluating the affective component of the cerebellar cognitive affective syndrome. J. Neuropsychiatry Clin. Neurosci. 2009, 21, 245-253. [CrossRef]

4. Marzban, H.; Del Bigio, M.R.; Alizadeh, J.; Ghavami, S.; Zachariah, R.M.; Rastegar, M. Cellular commitment in the developing cer-ebellum. Front. Cell. Neurosci. 2014, 8, 450.

5. Llinas, R.; Negrello, M.N. Cerebellum. Scholarpedia 2015, 10, 4606. [CrossRef]

6. Azevedo, F.A.C.; Carvalho, L.R.B.; Grinberg, L.T.; Farfel, J.M.; Ferretti, R.E.L.; Leite, R.E.P.; Filho, W.J.; Lent, R.; Herculano-Houzel, S. Equal numbers of neuronal and nonneuronal cells make the human brain an isometrically scaled-up primate brain. J. Comp. Neurol. 2009, 513, 532-541. [CrossRef] [PubMed]

7. Consalez, G.G.; Goldowitz, D.; Casoni, F.; Hawkes, R. Origins, Development, and Compartmentation of the Granule Cells of the Cerebellum. Front. Neural Circuits 2021, 14. [CrossRef] [PubMed]

8. Machold, R.; Fishell, G. Math1 Is Expressed in Temporally Discrete Pools of Cerebellar Rhombic-Lip Neural Progenitors. Neuron 2005, 48, 17-24. [CrossRef] [PubMed]

9. Yeung, J.; Ha, T.J.; Swanson, U.J.; Choi, K.; Tong, Y.; Goldowitz, D. Wls provides a new compartmental view of the rhombic lip in mouse cerebellar development. J. Neurosci. 2014, 34, 12527-12537. [CrossRef]

10. Yacubova, E.; Komuro, H. Cellular and molecular mechanisms of cerebellar granule cell migration. Cell Biophys. 2002, 37, 213-234. [CrossRef]

11. Espinosa, J.S.; Luo, L. Timing Neurogenesis and Differentiation: Insights from Quantitative Clonal Analyses of Cerebellar Granule Cells. J. Neurosci. 2008, 28, 2301-2312. [CrossRef] [PubMed]

12. Legué, E.; Riedel, E.; Joyner, A.L. Clonal analysis reveals granule cell behaviors and compartmentalization that determine the folded morphology of the cerebellum. Development 2015, 142, 1661-1671. [CrossRef]

13. Nakashima, K.; Umeshima, H.; Kengaku, M. Cerebellar granule cells are predominantly generated by terminal symmetric divisions of granule cell precursors. Dev. Dyn. 2015, 244, 748-758. [CrossRef]

14. Zanin, J.P.; Verpeut, J.L.; Li, Y.; Shiflett, M.W.; Wang, S.S.-H.; Santhakumar, V.; Friedman, W.J. The p75NTR Influences Cerebellar Circuit Development and Adult Behavior via Regulation of Cell Cycle Duration of Granule Cell Progenitors. J. Neurosci. 2019, 39, 9119-9129. [CrossRef] [PubMed]

15. Aguilar, A.; Meunier, A.; Strehl, L.; Martinovic, J.; Bonniere, M.; Attie-Bitach, T.; Encha-Razavi, F.; Spassky, N. Analysis of human samples reveals impaired SHH-dependent cerebellar development in Joubert syndrome/Meckel syndrome. Proc. Natl. Acad. Sci. USA 2012, 109, 16951-16956. [CrossRef]

16. Haldipur, P.; Bharti, U.; Govindan, S.; Sarkar, C.; Iyengar, S.; Gressens, P.; Mani, S. Expression of Sonic Hedgehog During Cell Proliferation in the Human Cerebellum. Stem Cells Dev. 2012, 21, 1059-1068. [CrossRef] [PubMed]

17. Lee, S.J.; Lindsey, S.; Graves, B.; Yoo, S.; Olson, J.M.; Langhans, S.A. Sonic Hedgehog-Induced Histone Deacetylase Activation Is Required for Cerebellar Granule Precursor Hyperplasia in Medulloblastoma. PLoS ONE 2013, 8, e71455. [CrossRef]

18. Lewis, P.M.; Gritli-Linde, A.; Smeyne, R.; Kottmann, A.; McMahon, A.P. Sonic hedgehog signaling is required for expansion of granule neuron precursors and patterning of the mouse cerebellum. Dev. Biol. 2004, 270, 393-410. [CrossRef] [PubMed]

19. Delogu, A.; Sellers, K.; Zagoraiou, L.; Bocianowska-Zbrog, A.; Mandal, S.; Guimera, J.; Rubenstein, J.L.; Sugden, D.; Jessell, T.; Lumsden, A. Subcortical Visual Shell Nuclei Targeted by ipRGCs Develop from a Sox14+-GABAergic Progenitor and Require Sox14 to Regulate Daily Activity Rhythms. Neuron 2012, 75, 648-662. [CrossRef] 
20. Vuong, T.A.; Leem, Y.-E.; Kim, B.-G.; Cho, H.; Lee, S.-J.; Bae, G.-U.; Kang, J.-S. A Sonic hedgehog coreceptor, BOC regulates neuronal differentiation and neurite outgrowth via interaction with ABL and JNK activation. Cell. Signal. 2017, 30, 30-40. [CrossRef]

21. Delloye-Bourgeois, C.; Rama, N.; Brito, J.; Le Douarin, N.; Mehlen, P. Sonic Hedgehog promotes the survival of neural crest cells by limiting apoptosis induced by the dependence receptor CDON during branchial arch development. Biochem. Biophys. Res. Commun. 2014, 452, 655-660. [CrossRef]

22. Xavier, G.M.; Seppala, M.; Papageorgiou, S.N.; Fan, C.-M.; Cobourne, M.T. Genetic interactions between the hedgehog coreceptors Gas1 and Boc regulate cell proliferation during murine palatogenesis. Oncotarget 2016, 7, 79233-79246. [CrossRef] [PubMed]

23. Wechsler-Reya, R.J.; Scott, M.P. Control of Neuronal Precursor Proliferation in the Cerebellum by Sonic Hedgehog. Neuron 1999, 22, 103-114. [CrossRef]

24. Corrales, J.D.; Rocco, G.L.; Blaess, S.; Guo, Q.; Joyner, A.L. Spatial pattern of sonic hedgehog signaling through Gli genes during cerebellum development. Development 2004, 131, 5581-5590. [CrossRef] [PubMed]

25. Altaba, A.R.I. Gli proteins encode context-dependent positive and negative functions: Implications for development and disease. Development 1999, 126, 3205-3216.

26. Ruppert, J.M.; Kinzler, K.W.; Wong, A.J.; Bigner, S.H.; Kao, F.T.; Law, M.L.; Seuanez, H.N.; O’Brien, S.J.; Vogelstein, B. The GLI-Kruppel family of human genes. Mol. Cell. Biol. 1988, 8, 3104-3113. [CrossRef]

27. Mimeault, M.; Batra, S.K. Frequent Deregulations in the Hedgehog Signaling Network and Cross-Talks with the Epidermal Growth Factor Receptor Pathway Involved in Cancer Progression and Targeted Therapies. Pharmacol. Rev. 2010, 62, 497-524. [CrossRef]

28. Carballo, G.B.; Honorato, J.R.; De Lopes, G.P.F.; Spohr, T.C.L.D.S.E. A highlight on Sonic hedgehog pathway. Cell Commun. Signal. 2018, 16, 1-15. [CrossRef]

29. Kenney, A.M. Nmyc upregulation by sonic hedgehog signaling promotes proliferation in developing cerebellar granule neuron precursors. Development 2003, 130, 15-28. [CrossRef]

30. Knoepfler, P.S.; Cheng, P.F.; Eisenman, R.N. N-myc is essential during neurogenesis for the rapid expansion of progenitor cell populations and the inhibition of neuronal differentiation. Genes Dev. 2002, 16, 2699-2712. [CrossRef]

31. Hatton, B.A.; Knoepfler, P.S.; Kenney, A.M.; Rowitch, D.H.; De Alborán, I.M.; Olson, J.M.; Eisenman, R.N. N-myc Is an Essential Downstream Effector of Shh Signaling during both Normal and Neoplastic Cerebellar Growth. Cancer Res. 2006, 66, 8655-8661. [CrossRef] [PubMed]

32. Pogoriler, J.; Millen, K.; Utset, M.; Du, W. Loss of cyclin D1 impairs cerebellar development and suppresses medulloblastoma formation. Development 2006, 133, 3929-3937. [CrossRef] [PubMed]

33. Otero, J.J.; Kalaszczynska, I.; Michowski, W.; Wong, M.; Gygli, P.E.; Gokozan, H.N.; Griveau, A.; Odajima, J.; Czeisler, C.; Catacutan, F.P.; et al. Cerebellar cortical lamination and foliation require cyclin A2. Dev. Biol. 2014, 385, 328-339. [CrossRef] [PubMed]

34. Ceccarelli, M.; Micheli, L.; D’Andrea, G.; De Bardi, M.; Scheijen, B.; Ciotti, M.; Leonardi, L.; Luvisetto, S.; Tirone, F. Altered cerebellum development and impaired motor coordination in mice lacking the Btg1 gene: Involvement of cyclin D1. Dev. Biol. 2015, 408, 109-125. [CrossRef] [PubMed]

35. Lübke, T.; Lobel, P.; Sleat, D.E. Proteomics of the lysosome. Biochim. Biophys. Acta (BBA) Bioenerg. 2009, 1793, 625-635. [CrossRef]

36. Saftig, P.; Klumperman, J. Lysosome biogenesis and lysosomal membrane proteins: Trafficking meets function. Nat. Rev. Mol. Cell Biol. 2009, 10, 623-635. [CrossRef]

37. Mannan, A.U.; Roussa, E.; Kraus, C.; Rickmann, M.; Maenner, J.; Nayernia, K.; Krieglstein, K.; Engel, W. Mutation in the gene encoding lysosomal acid phosphatase (Acp2) causes cerebellum and skin malformation in mouse. Neurogenetics 2004, 5, 229-238. [CrossRef]

38. Bailey, K.; Balaei, M.R.; Mehdizadeh, M.; Marzban, H. Spatial and Temporal Expression of Lysosomal Acid Phosphatase 2 (ACP2) Reveals Dynamic Patterning of the Mouse Cerebellar Cortex. Cerebellum 2013, 12, 870-881. [CrossRef] [PubMed]

39. Bailey, K.; Balaei, M.R.; Mannan, A.; Del Bigio, M.R.; Marzban, H. Purkinje Cell Compartmentation in the Cerebellum of the Lysosomal Acid Phosphatase 2 Mutant Mouse (Nax-Naked-Ataxia Mutant Mouse). PLoS ONE 2014, 9, e94327. [CrossRef]

40. Canterini, S.; Dragotto, J.; Dardis, A.; Zampieri, S.; De Stefano, M.E.; Mangia, F.; Erickson, R.P.; Fiorenza, M.T. Shortened primary cilium length and dysregulated Sonic hedgehog signaling in Niemann-Pick C1 disease. Hum. Mol. Genet. 2017, 26, 2277-2289. [CrossRef]

41. Yue, S.; Tang, L.-Y.; Tang, Y.; Tang, Y.; Shen, Q.-H.; Ding, J.; Chen, Y.; Zhang, Z.; Yu, T.-T.; E Zhang, Y.; et al. Requirement of Smurf-mediated endocytosis of Patched1 in sonic hedgehog signal reception. eLife 2014, 3. [CrossRef] [PubMed]

42. Roussel, M.F.; Hatten, M.E. Cerebellum. Curr. Top. Dev. Biol. 2011, 94, 235-282.

43. Ma, M.; Wu, W.; Li, Q.; Li, J.; Sheng, Z.; Shi, J.; Zhang, M.; Yang, H.; Wang, Z.; Sun, R.; et al. N-myc is a key switch regulating the proliferation cycle of postnatal cerebellar granule cell progenitors. Sci. Rep. 2015, 5, 12740. [CrossRef]

44. Mallet, J.; Huchet, M.; Pougeois, R.; Changeux, J.-P. Anatomical, physiological and biochemical studies on the cerebellum from mutant mice. III. Protein differences associated with the weaver, staggerer and nervous mutations. Brain Res. 1976, 103, 291-312. [CrossRef] 
45. Rahimi-Balaei, M.; Bergen, H.; Kong, J.; Marzban, H. Neuronal Migration During Development of the Cerebellum. Front. Cell. Neurosci. 2018, 12. [CrossRef]

46. Beachy, P.A.; Hymowitz, S.G.; Lazarus, R.A.; Leahy, D.J.; Siebold, C. Interactions between Hedgehog proteins and their binding partners come into view. Genes Dev. 2010, 24, 2001-2012. [CrossRef]

47. Zhao, X.; Heng, J.I.-T.; Guardavaccaro, D.; Jiang, R.; Pagano, M.; Guillemot, F.; Iavarone, A.; Lasorella, A. The HECT-domain ubiquitin ligase Huwe1 controls neural differentiation and proliferation by destabilizing the N-Myc oncoprotein. Nat. Cell Biol. 2008, 10, 643-653. [CrossRef]

48. Vriend, J.; Ghavami, S.; Marzban, H. The role of the ubiquitin proteasome system in cerebellar development and medulloblastoma. Mol. Brain 2015, 8, 1-14. [CrossRef]

49. Boon, K.; Caron, H.N.; Van Asperen, R.; Valentijn, L.; Hermus, M.-C.; Van Sluis, P.; Roobeek, I.; Weis, I.; Voûte, P.A.; Schwab, M.; et al. N-myc enhances the expression of a large set of genes functioning in ribosome biogenesis and protein synthesis. EMBO $J$. 2001, 20, 1383-1393. [CrossRef] [PubMed]

50. Corrales, J.D.; Blaess, S.; Mahoney, E.M.; Joyner, A.L. The level of sonic hedgehog signaling regulates the complexity of cerebellar foliation. Development 2006, 133, 1811-1821. [CrossRef] [PubMed]

51. Dahmane, N.; Altaba, A.R.I. Sonic hedgehog regulates the growth and patterning of the cerebellum. Development 1999, 126, 3089-3100. [PubMed]

52. Wallace, V.A. Purkinje-cell-derived Sonic hedgehog regulates granule neuron precursor cell proliferation in the developing mouse cerebellum. Curr. Biol. 1999, 9, 445-448. [CrossRef]

53. Chuang, P.-T.; McMahon, A.P. Vertebrate Hedgehog signalling modulated by induction of a Hedgehog-binding protein. Nat. Cell Biol. 1999, 397, 617-621. [CrossRef]

54. Wang, H.; Ge, G.; Uchida, Y.; Luu, B.; Ahn, S. Gli3 Is Required for Maintenance and Fate Specification of Cortical Progenitors. J. Neurosci. 2011, 31, 6440-6448. [CrossRef] [PubMed]

55. Jacob, J.; Briscoe, J. Gli proteins and the control of spinal-cord patterning. EMBO Rep. 2003, 4, 761-765. [CrossRef]

56. Borday, C.; Cabochette, P.; Parain, K.; Mazurier, N.; Janssens, S.; Tran, H.T.; Sekkali, B.; Bronchain, O.; Vleminckx, K.; Locker, M.; et al. Antagonistic cross-regulation between Wnt and Hedgehog signalling pathways controls post-embryonic retinal proliferation. Development 2012, 139, 3499-3509. [CrossRef]

57. Ocasio, J.K.; Bates, R.D.P.; Rapp, C.D.; Gershon, T.R. GSK-3 modulates SHH-driven proliferation in postnatal cerebellar neurogenesis and medulloblastoma. Development 2019, 146, dev177550. [CrossRef]

58. Anne, S.L.; Govek, E.-E.; Ayrault, O.; Kim, J.H.; Zhu, X.; Murphy, D.A.; Van Aelst, L.; Roussel, M.F.; Hatten, M.E. WNT3 Inhibits Cerebellar Granule Neuron Progenitor Proliferation and Medulloblastoma Formation via MAPK Activation. PLoS ONE 2013, 8 , e81769. [CrossRef]

59. Hu, M.C.; Mo, R.; Bhella, S.; Wilson, C.W.; Chuang, P.-T.; Hui, C.-C.; Rosenblum, N.D. GLI3-dependent transcriptional repression of Gli1, Gli2 and kidney patterning genes disrupts renal morphogenesis. Development 2006, 133, 569-578. [CrossRef]

60. Charron, J.; A Malynn, B.; Fisher, P.; Stewart, V.; Jeannotte, L.; Goff, S.P.; Robertson, E.J.; Alt, F.W. Embryonic lethality in mice homozygous for a targeted disruption of the N-myc gene. Genes Dev. 1992, 6, 2248-2257. [CrossRef]

61. Cohn, S.L.; Salwen, H.; Quasney, M.W.; Ikegaki, N.; Cowan, J.M.; Herst, C.V.; Kennett, R.H.; Rosen, S.T.; A DiGiuseppe, J.; Brodeur, G.M. Prolonged N-myc protein half-life in a neuroblastoma cell line lacking N-myc amplification. Oncogene 1990, 5, 1821-1827. [PubMed]

62. Sharma, T.; Schwalbe, E.C.; Williamson, D.; Sill, M.; Hovestadt, V.; Mynarek, M.; Rutkowski, S.; Robinson, G.W.; Gajjar, A.; Cavalli, F.; et al. Second-generation molecular subgrouping of medulloblastoma: An international meta-analysis of Group 3 and Group 4 subtypes. Acta Neuropathol. 2019, 138, 309-326. [CrossRef] [PubMed]

63. Lin, C.Y.; Erkek, S.; Tong, Y.; Yin, L.; Federation, A.J.; Zapatka, M.; Haldipur, P.; Kawauchi, D.; Risch, T.; Warnatz, H.-J.; et al. Active medulloblastoma enhancers reveal subgroup-specific cellular origins. Nat. Cell Biol. 2016, 530, 57-62. [CrossRef] [PubMed]

64. Oliver, T.G.; Grasfeder, L.L.; Carroll, A.L.; Kaiser, C.; Gillingham, C.L.; Lin, S.M.; Wickramasinghe, R.; Scott, M.P.; Wechsler-Reya, R.J. Transcriptional profiling of the Sonic hedgehog response: A critical role for N-myc in proliferation of neuronal precursors. Proc. Natl. Acad. Sci. USA 2003, 100, 7331-7336. [CrossRef]

65. Zhao, X.; Arca, D.D.; Lim, W.K.; Brahmachary, M.; Carro, M.S.; Ludwig, T.; Cardo, C.C.; Guillemot, F.; Aldape, K.; Califano, A.; et al. The N-Myc-DLL3 Cascade Is Suppressed by the Ubiquitin Ligase Huwe1 to Inhibit Proliferation and Promote Neurogenesis in the Developing Brain. Dev. Cell 2009, 17, 210-221. [CrossRef]

66. Mehdizadeh, M.; Ashtari, N.; Jiao, X.; Balaei, M.R.; Marzban, A.; Qiyami-Hour, F.; Kong, J.; Ghavami, S.; Marzban, H. Alteration of the Dopamine Receptors' Expression in the Cerebellum of the Lysosomal Acid Phosphatase 2 Mutant (Naked-Ataxia (NAX)) Mouse. Int. J. Mol. Sci. 2020, 21, 2914. [CrossRef]

67. Zhao, Z.; Lee, R.T.H.; Pusapati, G.V.; Iyu, A.; Rohatgi, R.; Ingham, P.W. An essential role for Grk2 in Hedgehog signalling downstream of Smoothened. EMBO Rep. 2016, 17, 739-752. [CrossRef]

68. Garcia-Lopez, J.; Kumar, R.; Smith, K.S.; Northcott, P.A. Deconstructing Sonic Hedgehog Medulloblastoma: Molecular Subtypes, Drivers, and Beyond. Trends Genet. 2021, 37, 235-250. [CrossRef]

69. Matsuo, S.; Takahashi, M.; Inoue, K.; Tamura, K.; Irie, K.; Kodama, Y.; Nishikawa, A.; Yoshida, M. Thickened area of external granular layer and Ki-67 positive focus are early events of medulloblastoma in Ptch1+/- mice. Exp. Toxicol. Pathol. 2013, 65, 863-873. [CrossRef] 
70. Iriana, S.; Asha, K.; Repak, M.; Sharma-Walia, N. Hedgehog Signaling: Implications in Cancers and Viral Infections. Int. J. Mol. Sci. 2021, 22, 1042. [CrossRef]

71. Balaei, M.R.; Jiao, X.; Ashtari, N.; Afsharinezhad, P.; Ghavami, S.; Marzban, H. Cerebellar Expression of the Neurotrophin Receptor p75 in Naked-Ataxia Mutant Mouse. Int. J. Mol. Sci. 2016, 17, 115. [CrossRef]

72. Emao, S.; Exiong, G.; Ezhang, L.; Edong, H.; Eliu, B.; Cohen, N.A.; Cohen, A.S. Verification of the Cross Immunoreactivity of A60, a Mouse Monoclonal Antibody against Neuronal Nuclear Protein. Front. Neuroanat. 2016, 10, 54. [CrossRef]

73. Moreno, N.; Joven, A.; Morona, R.; Bandín, S.; López, J.M.; González, A. Conserved localization of Pax6 and Pax7 transcripts in the brain of representatives of sarcopterygian vertebrates during development supports homologous brain regionalization. Front. Neuroanat. 2014, 8. [CrossRef] [PubMed]

74. Eberhardt, A.; Hansen, J.N.; Koster, J.; Jr, L.T.L.; Wang, S.; Livingstone, E.; Qian, K.; Valentijn, L.J.; Zheng, Y.G.; Schor, N.F.; et al. Protein arginine methyltransferase 1 is a novel regulator of MYCN in neuroblastoma. Oncotarget 2016, 7, 63629-63639. [CrossRef]

75. Chen, S.; Zhou, Y.; Chen, Y.; Gu, J. fastp: An ultra-fast all-in-one FASTQ preprocessor. Bioinform. 2018, 34, i884-i890. [CrossRef]

76. Liao, Y.; Smyth, G.K.; Shi, W. The Subread aligner: Fast, accurate and scalable read mapping by seed-and-vote. Nucleic Acids Res. 2013, 41, e108. [CrossRef] [PubMed]

77. Li, H.; Handsaker, B.; Wysoker, A.; Fennell, T.; Ruan, J.; Homer, N.; Marth, G.; Abecasis, G.; Durbin, R.; 1000 Genome Project Data Processing Subgroup. The Sequence Alignment/Map format and SAMtools. Bioinformatics 2009, 25, 2078-2079. [CrossRef]

78. Liao, Y.; Smyth, G.K.; Shi, W. featureCounts: An efficient general purpose program for assigning sequence reads to genomic features. Bioinformatics 2013, 30, 923-930. [CrossRef] [PubMed]

79. Eissa, N.; Hussein, H.; Rabbi, M.F.; Munyaka, P.M.; Khafipour, A.; Bernstein, C.N.; Ghia, J.-E. Tu1832 Stability of Reference Genes for Messenger RNA Quantification by Real-Time PCR in Mouse Dextran Sodium Sulfate Experimental Colitis. Gastroenterol. 2016, 150, S955-S956. [CrossRef]

80. Eissa, N.; Kermarrec, L.; Hussein, H.; Bernstein, C.N.; Ghia, J.-E. Appropriateness of reference genes for normalizing messenger RNA in mouse 2,4-dinitrobenzene sulfonic acid (DNBS)-induced colitis using quantitative real time PCR. Sci. Rep. 2017, 7, 42427. [CrossRef] [PubMed]

81. Abu-El-Rub, E.; Sequiera, G.L.; Sareen, N.; Yan, W.; Moudgil, M.; Sabbir, M.G.; Dhingra, S. Hypoxia-induced 26S proteasome dysfunction increases immunogenicity of mesenchymal stem cells. Cell Death Dis. 2019, 10, 1-17. [CrossRef] [PubMed]

82. Abu-El-Rub, E.; Sareen, N.; Yan, W.; Alagarsamy, K.N.; Rafieerad, A.; Srivastava, A.; Desiderio, V.; Dhingra, S. Hypoxia-induced shift in the phenotype of proteasome from 26S toward immunoproteasome triggers loss of immunoprivilege of mesenchymal stem cells. Cell Death Dis. 2020, 11, 1-12. [CrossRef] [PubMed] 